RAFAELLA NASCIMENTO E Silva

\title{
Glaucoma em pacientes com aniridia e ceratoprótese de Boston tipo 1
}

Tese apresentada à Faculdade de Medicina da Universidade de São Paulo para obtenção do título de Doutor em Ciências

Programa de Oftalmologia

Orientador: Prof. Dr. Milton Ruiz Alves

São Paulo 2019 
Dados Internacionais de Catalogação na Publicação (CIP)

Preparada pela Biblioteca da

Faculdade de Medicina da Universidade de São Paulo

Creprodução autorizada pelo autor

Silva, Rafaella Nascimento e

Glaucoma em pacientes com aniridia e

ceratoprótese de Boston tipo 1 / Rafaella Nascimento

e Silva. -- São Paulo, 2019.

Tese (doutorado)--Faculdade de Medicina da

Universidade de São Paulo.

Programa de Oftalmologia.

Orientador: Milton Ruiz Alves.

Descritores: 1.Aniridia 2.Doenças da

córnea/cirurgia 3.Córnea/cirurgia 4.Próteses e

implantes 5. Glaucoma

$\mathrm{USP} / \mathrm{FM} / \mathrm{DBD}-343 / 19$

Responsável: Erinalva da Conceição Batista, CRB-8 6755 
Aos meus pais, Rosangela e André, pelos pilares educacionais $\mathrm{e}$ pelo incentivo a meus potenciais. 


\section{Agradecimentos}

Ao Professor Doutor Milton Ruiz Alves, modelo de liderança, humanismo e ética; por me conceder a inestimável oportunidade de sua orientação para realização de um sonho.

Ao Ricardo Noguera Louzada, pelo constante apoio, companheirismo e cumplicidade.

Aos irmãos Matheus Nascimento e Silva e Marcella Nascimento e Silva, por serem meus melhores amigos.

Às queridas Filomena Lourenço dos Santos Raso, Jussara Almeida Chaves Pereira, Silvia Augusta do Nascimento, Juliana Aparecida da Silva Moreira, Jânia Maria Silva da Luz, e aos demais amigos e familiares, pelas vibrações de amor.

À Doutora Lucy Qing Shen, Hospital Massachusetts Eye and Ear, Harvard Medical School, mentora, fundamental na minha formação, por ter me dado a oportunidade de um rico aprendizado adquirido sob sua orientação.

Ao Professor Doutor Emérito Claes Henrik Dohlman, fonte de sabedoria e inspiração, por ser o pioneiro em várias inovações cirúrgicas, como a ceratoprótese de Boston, a benefício de milhares de pacientes.

Aos Doutores Louis Robert Pasquale e James Chodosh, a minha sincera gratidão pelos grandes ensinamentos transmitidos no desenvolvimento dos trabalhos científicos.

Aos colaboradores Carolina Altagracia Chiou, Swapna Satish Shanbhag, Eleftherios Paschalis Ilios, Kathryn Colby, pelo auxílio na realização deste projeto. 
Ao Professor Doutor Mário Luiz Ribeiro Monteiro, pela dedicação ao ensino e pesquisa.

Ao Professor Doutor Remo Susanna Jr., por ser um modelo de liderança e de atuação mundial na Oftalmologia.

À Regina Ferreira de Almeida, por ser um exemplo de profissionalismo e devoção à pós-graduação. 


\section{Normatização}

Esta tese está de acordo com as seguintes normas, em vigor no momento desta publicação:

Referências: adaptado de International Committee of Medical Journals Editors (Vancouver).

Universidade de São Paulo: Faculdade de Medicina. Divisão de Biblioteca e Documentação. Guia de apresentação de dissertações, teses e monografias. Elaborado por: Anneliese Carneiro da Cunha; Maria Julia de A. L. Freddi; Maria F. Crestana; Marinalva de Souza Aragão; Suely Campos Cardoso; Valéria Vilhena. 3. ed. São Paulo: Divisão de Biblioteca e Documentação, 2011.

Abreviatura dos títulos e periódicos de acordo com List of Journals Indexed in Index Medicus. 


\section{Sumário}

Lista de Abreviaturas, Siglas e Símbolos

Lista de Tabelas

Lista de Figuras

Resumo

Abstract

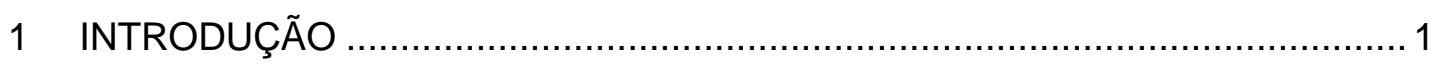

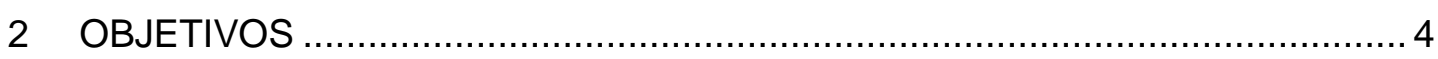

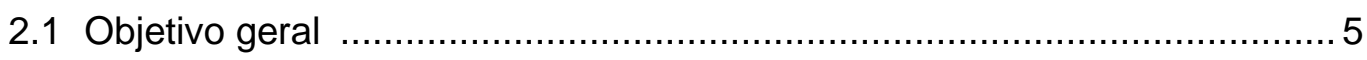

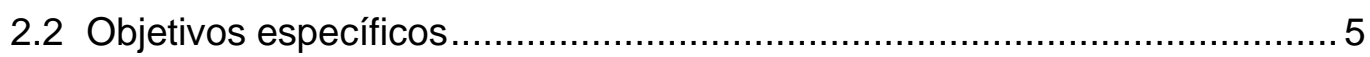

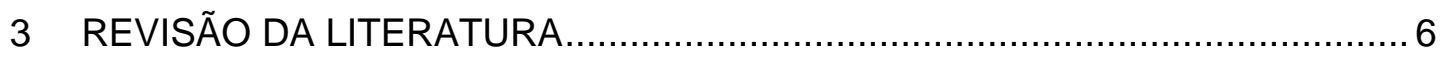

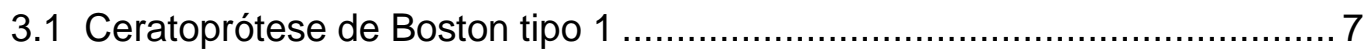

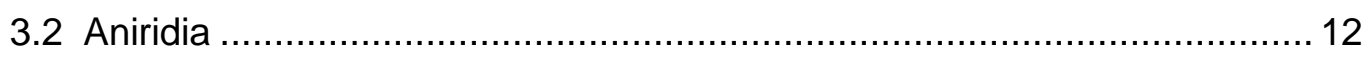

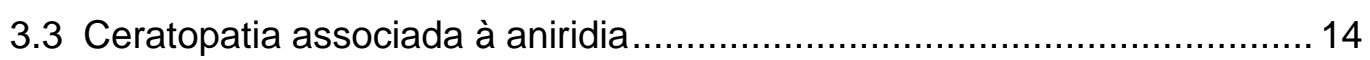

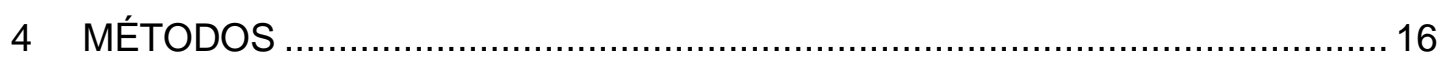

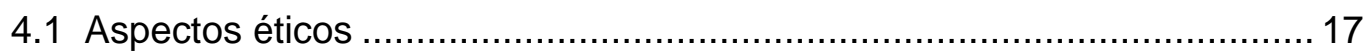

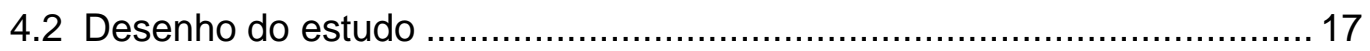

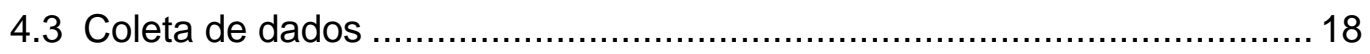

4.4 Critérios para definição de glaucoma preexistente …………………....... 19

4.5 Critérios para definição de progressão e diagnóstico de glaucoma ........... 19

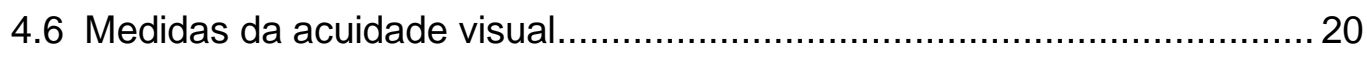

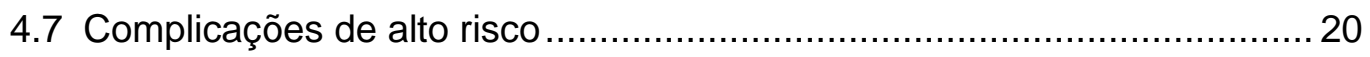

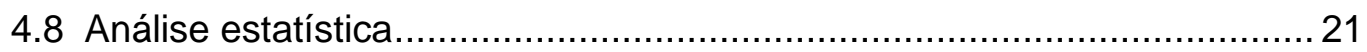

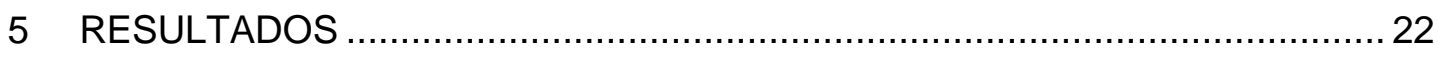

5.1 Dados demográficos, pré-operatórios, perioperatórios, pós-

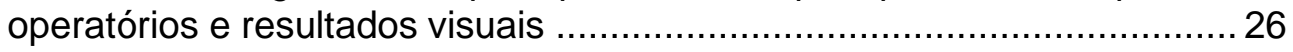

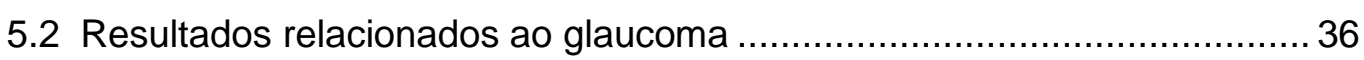

5.3 Implante de drenagem para glaucoma e manejo das complicações

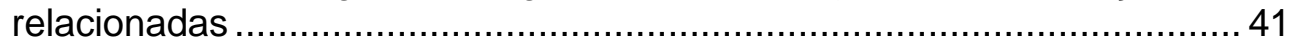

5.4 Outras complicações após a cirurgia de B-KPro tipo 1 ............................ 43

5.5 Tratamento com equipe composta por especialistas em córnea,

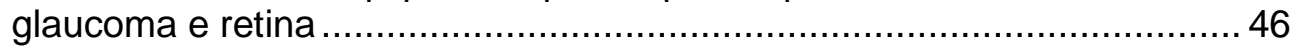

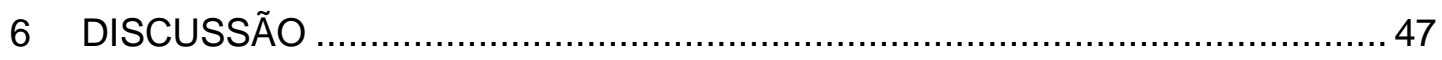

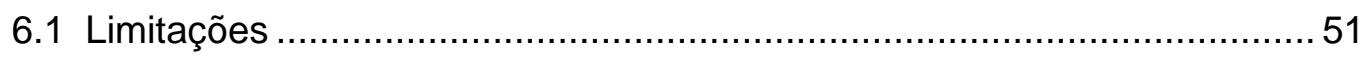




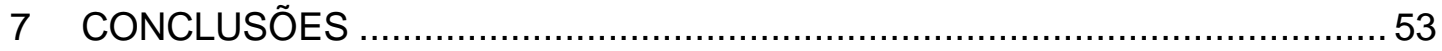

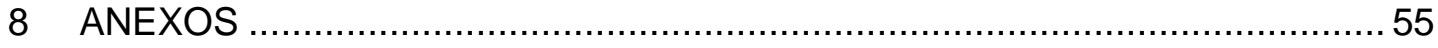

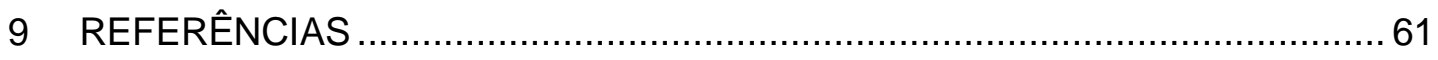

APÊNDICE 


\section{Listas}

\section{ABREVIATURAS, SIGLAS E SÍMBOLOS}

\begin{tabular}{ll} 
AV & Acuidade visual \\
B-KPro & Ceratoprótese de Boston (Boston Keratoprosthesis) \\
CA & Câmara anterior \\
CD & Conta dedos \\
DP & Desvio padrão \\
E/D & Escavação/disco \\
et al. & E outros \\
FDA & Regulamentação de Alimentos e Fármacos nos Estados \\
IRB & Unidos da América (Food and Drug Administration) \\
LogMAR & Conselho de Revisão Institucional (Institutional Review \\
MM & Loard) \\
ND & Movimento de mãos \\
PAX 6 & Não disponível \\
PIO & Gene Paired Box 6 \\
PL & Pressão intraocular \\
PMMA & Percepção luminosa \\
SPL & Polimetilmetacrilato \\
\% & Sem percepção luminosa \\
\hline & Porcentagem \\
\hline
\end{tabular}




$\begin{array}{ll}> & \text { Maior } \\ = & \text { Sinal de igual } \\ \pm & \text { Mais ou menos } \\ \leq & \text { Menor ou igual } \\ \geq & \text { Maior ou igual } \\ \mathrm{mm} & \text { Milímetro } \\ \mathrm{mmHg} & \text { Milímetro de mercúrio } \\ \mathrm{n} & \text { Número } \\ \mathrm{vs} . & \text { Versus } \\ \mu \mathrm{m} & \text { Micrômetro }\end{array}$




\section{TABELAS}

Tabela 1 - Características dos olhos submetidos à ceratoprótese de Boston tipo 1 com falência de retenção ou phthisis, dentro de 2 anos após a cirurgia

Tabela 2 - Número de casos por indicação da ceratoprótese de Boston (B-KPro) tipo 1 no grupo comparativo

Tabela 3 - Dados demográficos, pré-operatórios, perioperatórios, pós-operatórios e resultados visuais relacionados ao implante da ceratoprótese

Tabela 4 - Causas potenciais de baixa visão $(<20 / 200)$ em ambos os grupos

Tabela 5 - A análise comparativa da acuidade visual final com a medida pré-operatória por indicação

Tabela 6 - Dados dos grupos relacionados ao glaucoma

Tabela 7 - Resultados dos implantes de drenagem para glaucoma

Tabela 8 - Prevalência cumulativa de complicações com risco de perda visual após a cirurgia de implante da ceratoprótese de Boston tipo 1

Tabela 9 - Descrição dos casos de descolamento de coroide ou hemorragia supracoroidiana relacionados à hipotonia 45

Tabela 10 - Avaliação pelos especialistas em glaucoma e retina 46 
FIGURAS

Figura 1 - Ceratoprótese de Boston tipo 1. A figura demonstra: a peça frontal com zona óptica central (A); a placa posterior com 16 fenestrações $(B)$; o anel de travamento de titânio (C); a ceratoprótese montada com a córnea doadora (D). 8

Figura 2 - Acuidade visual melhor que percepção luminosa (PL) após cirurgia de ceratoprótese tipo 1 de Boston nos grupos aniridia e comparativo. As curvas de Kaplan-Meier comparam a proporção de olhos nos grupos aniridia (linha azul) e comparativo (linha vermelha) ao longo do tempo que retiveram uma melhor acuidade visual corrigida melhor que PL. Ambos os grupos apresentaram similar taxa de retenção ( $p=0,36$, teste de log-rank)

Figura 3 - Acuidade visual melhor ou igual a 20/200 após cirurgia de ceratoprótese tipo 1 de Boston nos grupos aniridia e comparativo. As curvas de Kaplan-Meier comparam a proporção de olhos nos grupos aniridia (linha azul) e comparativo (linha vermelha) ao longo do tempo que retiveram uma melhor acuidade visual corrigida melhor ou igual a 20/200. Ambos os grupos apresentaram similar taxa de retenção ( $p=0,71$, teste de log-rank) 
Figura 4 - Relação escavação/disco (E/D) menor ou igual a 0.8 após cirurgia de ceratoprótese tipo 1 de Boston nos grupos aniridia e comparativo. As curvas de Kaplan-Meier comparam a proporção de olhos nos grupos aniridia (linha azul) e comparativo (linha vermelha) ao longo do tempo que retiveram uma $E / D$ menor ou igual a 0,8 . Ambos os grupos apresentaram similares proporções ao longo dos meses ( $p=0,51$, teste de log-rank) 39

Figura 5 - Progressão da relação escavação/disco (E/D) menor que 0,2 após cirurgia de ceratoprótese tipo 1 de Boston nos grupos aniridia e comparativo. As curvas de Kaplan-Meier comparam a proporção de olhos nos grupos aniridia (linha azul) e comparativo (linha vermelha) ao longo do tempo que retiveram uma progressão na $E / D$ menor que 0,2. Ambos os grupos apresentaram similares proporções ao longo dos meses ( $p=0,92$, teste de log-rank) 


\section{Resumo}

Silva RN. Glaucoma em pacientes com aniridia e ceratoprótese de Boston tipo 1 [tese]. São Paulo: Faculdade de Medicina, Universidade de São Paulo; 2019.

OBJETIVO: Comparar os resultados e o tratamento do glaucoma em olhos com aniridia após o implante de ceratoprótese de Boston (B-KPro) tipo 1. MÉTODOS: Estudo retrospectivo envolvendo pacientes submetidos ao implante B-KPro tipo $1 \mathrm{com}$ placa posterior de titânio entre outubro de 2007 e dezembro de 2015 no hospital Massachusetts Eye and Ear, Boston, Estados Unidos da América, com pelo menos, 2 anos de acompanhamento. Foram inclusos pacientes com aniridia e pacientes com outros diagnósticos pré-operatórios (excluindo síndrome de Stevens-Johnson, penfigoide ocular cicatricial e distúrbios congênitos com distorção angular). Um olho por paciente foi selecionado pelo maior tempo de seguimento. $O$ teste de Shapiro-Wilk foi utilizado para testar a distribuição normal das variáveis contínuas. O teste t para comparar as variáveis com distribuição normal e o teste Wilcoxon para comparar as variáveis com distribuição não normal. 0 teste Qui-quadrado de Pearson foi utilizado para comparar as variáveis categóricas entre os grupos. RESULTADOS: Os grupos aniridia $(n=22)$ e comparativo $(n=61)$ apresentaram semelhantes tempo de seguimento (média \pm desvio-padrão, 70,7 \pm 28,6 meses, 63,8 $\pm 25,5$ meses, respectivamente, $p=0,25)$ e acuidade visual $(A V)$ pré-operatória $(1,85 \pm$ $0,35 \log M A R ; 1,87 \pm 0,57 \log M A R ; p=0,33$. Antes da cirurgia, os olhos com aniridia apresentaram mais glaucoma $(76,2 \%)$ e cirurgia relacionada ao glaucoma $(57,1 \%)$ que os olhos do grupo comparativo $(51,8 \%, p=0,053$; $23,2 \%, p=0,005$; respectivamente). Mais tubo de drenagem para glaucoma foram implantados concomitantemente à B-KPro em olhos com aniridia $(47,6 \%)$ versus olhos do grupo comparativo $(17,9 \%, p=0,008)$. No final do seguimento, mais olhos do grupo aniridia apresentaram glaucoma $(90,5 \%)$ e, pelo menos, uma cirurgia de glaucoma antes, durante ou após o implante da B-Kpro $(90,5 \%)$, comparados ao segundo grupo $(64,3 \%, p=0,02 ; 53,6 \%$, $p$ $=0,003$ ). Entretanto, ambos obtiveram porcentagens similares de olhos com relação escavação-disco $(E / D)>0,8(23,8 \%$ vs. $30,4 \%, p=0,57)$ ou progressão da $E / D \geq 0,2$ ( $42,9 \%$ vs. $44,6 \%, p=0,89)$. Nenhum dos olhos com implante de tubo profilático desenvolveu glaucoma. As porcentagens de olhos com, pelo menos, uma complicação de alto risco foram $45,5 \%$ no grupo aniridia versus $26,2 \%$ no grupo comparativo $(p=0,10)$. Olhos com e sem aniridia não diferiram na melhora da AV após a B-KPro (72,7\%; 72,1\%; $p=0,96)$, e sua medida final $(1,28 \pm 0,79 \log M A R ; 1,23 \pm 0,98 \log M A R ; p=$ 0,51). CONCLUSÕES: Apesar de uma alta prevalência de glaucoma e outras complicações de alto risco, a B-KPro tipo 1 oferece uma reabilitação visual satisfatória em pacientes com aniridia quando o controle do glaucoma e de outras complicações é realizado de forma agressiva por uma equipe de especialistas treinados.

Descritores: 1. Aniridia; 2. Doenças da córnea/cirurgia; 3. Córnea/cirurgia; 4. Próteses e implantes; 5. Glaucoma. 


\section{Abstract}

Silva RN. Glaucoma in patients with aniridia and Boston type 1 keratoprosthesis [thesis]. São Paulo: "Faculdade de Medicina, Universidade de São Paulo"; 2019.

PURPOSE: To compare outcomes related to glaucoma and glaucoma management in eyes with aniridia after Boston Keratoprosthesis (B-KPro) type 1 implantation. METHODS: Eyes with titanium backplate B-KPro type 1 implanted between October 2007 and December 2015 at Massachusetts Eye and Ear, Boston, United States, with more than 2 years of follow-up, were retrospectively studied. Chart data was reviewed for patients with aniridia and patients with other preoperative diagnoses (excluding Stevens-Johnson syndrome, mucous membrane pemphigoid, and congenital ocular disorders with angle distortion). One eye per patient was selected by the longest followup time. The normality of continuous variables was assessed with the Shapiro-Wilk test. $T$ test was used to compare normally distributed continuous variables and Wilcoxon rank-sum test for non-normally distributed variables. The Pearson chi-square test was used to compare categorical variables between groups. RESULTS: The groups aniridia $(n=22)$ and comparative $(n=61)$ had similar follow-up time (mean \pm standard deviation; $70.7 \pm 28.6$ months; $63.8 \pm 25.5$ months, respectively, $p=0.25$ ) and preoperative visual acuity (VA, $1.85 \pm 0.35 \log M A R ; 1.87 \pm 0.57 \log M A R ; p=$ 0.33). Prior to B-KPro surgery, aniridic eyes showed higher rates of glaucoma diagnosis (76.2\%) and glaucoma surgery $(57.1 \%)$ compared to the second group $(51.8 \%, p=0.053 ; 23.2 \%, p=0.005$, respectively). There was more co-implantation of glaucoma drainage devices concomitantly with BKPro in aniridia (47.6\%) versus comparison eyes $(17.9 \%, p=0.008)$. At the final follow-up visit, more eyes with aniridia had glaucoma $(90.5 \%)$ and at least one glaucoma surgery before, during, or after B-KPro implantation (90.5\%), than comparison eyes $(64.3 \%, p=0.02 ; 53.6 \%, p=0.003)$. However, both obtained similar rates of cup to disc ratio (CDR) $>0.8(23.8 \%$ vs. $30.4 \%, p=0.57)$ or progression of $C D R \geq 0.2(42.9 \%$ vs. $44.6 \%, p=$ $0.89)$. None of the eyes with prophylactic tube developed glaucoma. The percentages of eyes with at least one serious vision threatening complication were $45.5 \%$ in the aniridia group versus $26.2 \%$ in the comparative group ( $p=$ $0.10)$. Despite this, the two groups had similar percentages of eyes with VA improvement $(72.7 \%, 72.1 \%, p=0.96)$, and similar postoperative VA at the end of follow-up (1.28 $\pm 0.79 \log M A R, 1.23 \pm 0.98 \log M A R, p=0.51)$. CONCLUSIONS: Despite a high prevalence of glaucoma and other vision threatening complications, B-KPro type 1 surgery can lead to long-term visual rehabilitation in patients with aniridia when a team of trained specialists is available to manage glaucoma and other complications.

Descriptors: 1. Aniridia; 2. Corneal diseases/surgery; 3. Cornea/surgery; 4. Prostheses and implants; 5. Glaucoma. 
1 Introdução 


\section{INTRODUÇÃO}

A aniridia congênita é uma doença ocular resultante sobretudo de variações no gene Paired Box 6 (PAX 6) no cromossomo 11 1, 2 . Sua característica marcante é a ausência quase completa ou parcial da íris e possui uma incidência estimada de 1 caso em 64.000 a 96.000 pessoas $^{3,4}$.

$\mathrm{Na}$ infância, a acuidade visual (AV) na aniridia, inicialmente, é reduzida e acompanhada de nistagmo, sobretudo atribuída pela gravidade da hipoplasia foveal ${ }^{2,3,5,6}$. Posteriormente, continua a declinar em razão do surgimento de outras afecções oculares, como o glaucoma, a ceratopatia e a catarata $^{2,3,5,6}$.

A incidência de glaucoma na aniridia é alta de, aproximadamente, $50 \%$ (variando entre $6 \%$ e $75 \%$ ), e é atribuída ao fechamento angular por rotação anterior gradual do remanescente da íris, embora outros mecanismos tenham sido sugeridos $3,5,7,8$. A ceratopatia é causada pela disfunção de células-tronco do limbo, e manifesta-se gradativamente com espessamento e vascularização do epitélio periférico até o acometimento da córnea central com fibrose subepitelial e formação de cicatriz estromal profunda com acometimento visual ${ }^{9-11}$. Já foram propostos vários tratamentos para a cerotopatia, mas com sucesso limitado, como, por exemplo, a ceratoplastia penetrante, que apresentou uma taxa de recorrência da doença e de falência da córnea entre $64 \%$ e 100\% dos casos ${ }^{12,13}$. Técnicas de transplante limbares, como o transplante alógeno 
ceratolímbico de doador cadáver, requerem terapia imunossupressora para estabilidade da superfície ocular, e estão associadas a altas taxas de rejeição e falência, sobretudo em pacientes jovens e sem boa adesão ao tratamento $10,14,15$.

Nesse cenário, por não exigir imunossupressão, uma importante opção para o tratamento dessa ceratopatia é o implante da ceratoprótese de Boston (B-KPro, Massachusetts Eye and Ear, Estados Unidos da América) tipo 1 16, 17. Entretanto, a prevalência de glaucoma pré-operatório em olhos com aniridia submetidos a esse implante é relatada entre $78 \%$ e $81 \%{ }^{18,19}$, o que é maior quando comparada às outras indicações, descritas entre $36 \%$ e $76 \%{ }^{20-23}$.

Além da alta prevalência nesse grupo de pacientes, o diagnóstico e 0 acompanhamento do glaucoma são desafiadores. A medida da pressão intraocular (PIO) com tonômetros padrões é impossibilitada pela rigidez da placa posterior. A alternativa é a medida subjetiva com palpação digital da esclera ${ }^{24}$. Além disso, a avaliação do nervo óptico e o exame de campo visual podem ser limitados pelo diâmetro da zona óptica da B-KPro tipo 1, assim como pelo possível surgimento da membrana retroprotética, ou pela dificuldade de fixação causada pelo nistagmo ${ }^{24}$. Após o implante da B-KPro tipo 1, o glaucoma também foi reportado como uma das principais causas de perda visual nesse grupo de pacientes ${ }^{25}$.

Assim, um estudo dos casos de ceratopatia associada à aniridia submetidos ao implante da B-KPro tipo 1, dirigido ao monitoramento e ao tratamento do glaucoma, é necessário para avaliar o prognóstico dessa opção terapêutica. 
2 Objetivos 
2 OBJETIVOS

\subsection{Objetivo geral}

- Avaliação retrospectiva dos casos de ceratopatia associada à aniridia submetidos à B-KPro tipo 1 na instituição Massachusetts Eye and Ear, Boston, Estados Unidos da América.

\subsection{Objetivos específicos}

- Analisar os resultados intermediários e de longo prazo relacionados ao glaucoma e seu tratamento.

- Avaliar os dados demográficos, pré-operatórios, perioperatórios, pósoperatórios e os resultados visuais.

- Comparar os resultados dos casos de ceratopatia associada à aniridia com o grupo comparativo, composto por todos os casos com outras indicações da B-KPro tipo 1, excluindo doenças oculares congênitas com distorção angular, síndrome de Stevens-Johnson e penfigoide ocular cicatricial. 
3 Revisão da Literatura 


\section{REVISÃO DA LITERATURA}

\subsection{Ceratoprótese de Boston tipo 1}

Aprovada pelo órgão regulador americano Food and Drug Administration (FDA), em 1992, e submetida às modificações no design, com consequente melhora dos resultados, a ceratoprótese de Boston tipo 1 atualmente é a ceratoprótese mais implantada no mundo, com mais de 14 mil implantes ${ }^{26-28 .}$

Em sua configuração atual, a córnea doadora é posicionada entre uma peça frontal de polimetilmetacrilato (PMMA), com uma zona óptica central de 3,35 mm, e uma placa posterior de titânio ou PMMA, disponíveis nos diâmetros de 7 mm (8 fenestrações de 1,3 mm de diâmetro) e de 8,5 mm (16 fenestrações de 1,17 mm de diâmetro), ambas com a necessidade de um anel de travamento de titânio (Figura 1) 27, 29, 30. As fenestrações permitem a nutrição da córnea doadora por meio do humor aquoso 27, 29,30 . Há também o modelo com placa posterior de 8,5 mm de titânio em formato especial para o travamento sem necessidade do anel ${ }^{31}$. A placa posterior de titânio é mais fina $(0,25 \mathrm{~mm})$ que o modelo de PMMA $(0,9 \mathrm{~mm})$, e está associada a um menor desenvolvimento de membrana retroprotética, embora não tenha sido demonstrada diferença significativa na alteração da anatomia angular entre os dois modelos ${ }^{31,32}$. As próteses são fabricadas em 
modelos para pseudofácico, com poder dióptrico único da peça frontal, e para afácicos, com poder dióptrico calculado pelo comprimento axial ${ }^{29,33}$.

A
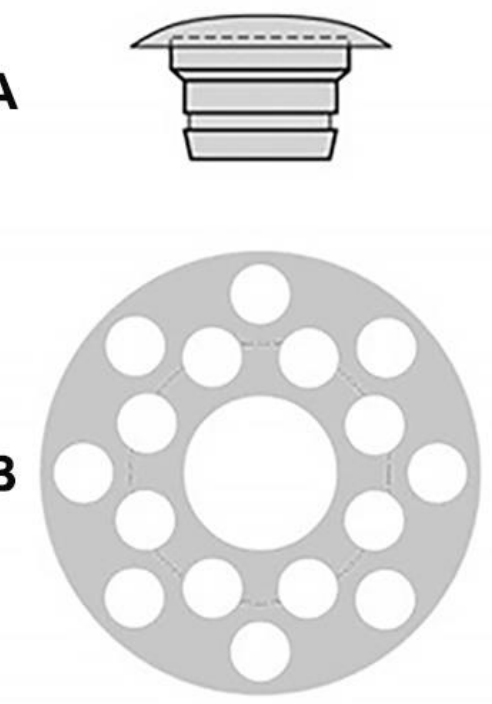

C
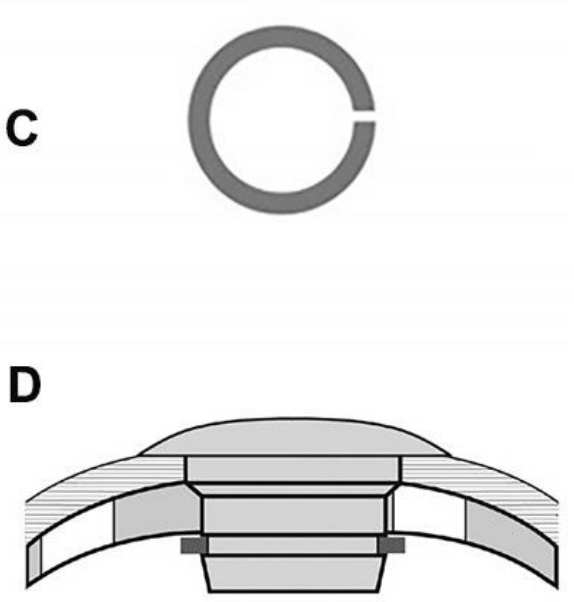

FONTE: Cortesia de Massachusetts Eye and Ear Boston Keratoprosthesis ${ }^{29}$

Figura 1 - Ceratoprótese de Boston tipo 1. A figura demonstra: a peça frontal com zona óptica central (A); a placa posterior com 16 fenestrações (B); o anel de travamento de titânio (C); a ceratoprótese montada com a córnea doadora (D)

A técnica de montagem e os passos cirúrgicos são descritos na literatura ${ }^{34,35}$. Primeiramente, a ceratoprótese deve ser montada antes da trepanação da córnea receptora. Em resumo, um orifício central é trepanado 
com um punch dermatológico de $3 \mathrm{~mm}$ na córnea doadora, com geralmente 8,5-9 $\mathrm{mm}$ de diâmetro, intencionada para um leito receptor $0,5 \mathrm{~mm}$ menor (8-8,5 mm). Então, para facilitar a montagem, a peça frontal é posicionada com a superfície anterior para baixo e aderida a um adesivo estéril. Em seguida, a córnea doadora com orifício central é gentilmente empurrada sobre a haste da peça frontal. Viscoelástico pode ser aplicado na superfície endotelial da córnea doadora. Sucessivamente, a placa posterior é colocada sem aplicar nenhum movimento rotativo sobre a córnea doadora. O anel de travamento de titânio é o componente final e o mais posterior da instalação. Dentro da embalagem da B-KPro tipo 1, é fornecida uma ferramenta cilíndrica com orifício interno para auxiliar a montagem evitando pressão excessiva. A decisão de manter o paciente afácico ou pseudofácico deve ser feita no pré-operatório para a escolha do poder dióptrico adequado. Então, o complexo córnea-ceratoprótese deve ser suturado (usualmente, 16 suturas interrompidas) com fio náilon 9-0 ou 10-0. Ao final da cirurgia, deve-se colocar uma lente de contato plana terapêutica de grande diâmetro, geralmente, de $16 \mathrm{~mm}$ de diâmetro e $9,8 \mathrm{~mm}$ de curvatura.

Implantes de tubo de drenagem para glaucoma podem ser realizados concomitantemente à cirurgia de B-Kpro tipo 1, e podem ser implantados na câmara anterior ou posteriormente na pars plana ${ }^{36,37}$. Caso for optado pela técnica de implante na pars plana, a técnica de sutura do prato é descrita antes da trepanação da córnea, e a inserção do tubo, após o implante da BKPro tipo 1 e a vitrectomia ${ }^{36}$. A visualização direta, por meio da ceratoprótese ou pela técnica de transiluminação auxilia a introdução segura 
de uma agulha de calibre 23 gauge na pars plana a, aproximadamente, 5 $\mathrm{mm}$ do limbo ${ }^{36}$.

Suas principais indicações são pacientes com alto risco de rejeição ou falência de transplante de córnea, aniridia, ceratite herpética, trauma e queimadura ocular 38, 39. Pacientes com síndrome de Stevens-Johnson e penfigoide ocular cicatricial, por terem uma produção lacrimal insuficiente, são considerados de alto risco para o implante da B-KPro tipo 1 e, normalmente são tratados com o implante tipo 2, modelo transpalpebral, para reduzir o risco de necrose estromal e extrusão ${ }^{40}$. Apesar de as B-KPro tipo 1 e 2 serem as mais utilizadas, há também outros modelos implantados no mundo, como a osteo-odonto ceratoprótese (Singapore National Eye Centre, Singapura), e a AlphaCor® ceratoprostese (Argus Biomedical Pty. Ltd., Austrália) 30, 41-43. Recentemente, vêm surgindo novos tipos, como a KeraKlear® (Keramed, Estados Unidos da América) ${ }^{44}$.

Antes da realização da cirurgia, é de extrema importância que o paciente entenda e aceite o acompanhamento e o cuidado ocular contínuo, com o uso de antibióticos e lente de contato gelatinosa 45, 46. No pósoperatório, o uso tópico de acetato de prednisolona a 1\% deve ser usado quatro vezes ao dia, pelo menos, durante o primeiro mês da cirurgia, diminuindo o número de aplicações ao longo dos primeiros 6 meses ${ }^{27,}{ }^{35}$. 0 regime e a escolha do antibióticos variam entre os cirurgiões, entretanto eles devem ser usados profilaticamente por toda a vida, por reduzir significativamente o risco de endoftalmite ${ }^{45}$. No hospital Massachusetts Eye and Ear, para o regime profilático, é recomendado o uso de fluoroquinolona 
ou sulfato de polimixina $b+$ trimetoprima uma vez ao dia ${ }^{27}$. Em casos de alto risco, como em doenças autoimunes ou em pacientes monoculares, pode-se indicar também o uso combinado de vancomicina (concentração $14 \mathrm{mg} / \mathrm{ml}$ com o conservante cloreto de benzalcônio) 27,47 . Não existe consenso em relação à profilaxia fúngica de rotina. Em regiões endêmicas, o hospital Massachusetts Eye and Ear recomenda ciclos de antifúngicos tópicos, como a natamicina a $5 \%$ ou anfotericina a $0,15 \%$, administrados duas vezes ao dia por uma semana a cada 3 meses 47,48 . Nas visitas clínicas, caso ocorra manipulação ocular, como a substituição de uma lente de contato, recomenda-se o uso de colírios antibióticos ou de iodopovidona a $5 \%{ }^{27}$. O uso contínuo de lente de contato terapêutica mantém a hidratação da córnea, o que previne a formação de dellen adjacente à peça frontal, defeitos epiteliais crônicos e necrose estromal 46, 49, 50. Além disso, ela pode corrigir eventuais erros refrativos, reduzir a dispersão da luz, aumentar o conforto do paciente, e, quando colorida, pode ter função cosmética ${ }^{50}$. Mas, em razão do potencial depósito de proteínas e biofilmes inflamatórios, as lentes devem ser rotineiramente trocadas a cada 3-4 meses ${ }^{27,}$,7. Em pacientes com implantes de drenagem, há também o risco de erosões conjuntivais ao longo do tubo ocasionadas por possível fricção mecânica da lente de contato, com exigência de tratamento com troca do diâmetro da lente, aumento da lubrificação ou necessidade de revisão cirúrgica ${ }^{51,52}$.

Com as melhorias no design e nas orientações pós-operatórias, houve uma redução significativa das complicações agudas, como a 
endoftalmite e a necrose estromal $21,45,53$. Nesse cenário, o prognóstico visual passou a ser limitado por complicações crônicas, como o glaucoma 25,54 . A prevalência de glaucoma é alta, presente entre $36 \%$ e $76 \%$ dos olhos antes da cirurgia de B-KPro tipo 1, e desenvolvido entre $21 \%$ e $75 \%$ dos olhos não previamente glaucomatosos $20-23,55,56$. Além da alta prevalência, o diagnóstico e o acompanhamento do glaucoma são dificultados pela impossibilidade de medir a PIO com tonômetros padrões em razão da rigidez da placa posterior. Assim, a alternativa é a medida subjetiva com palpação digital da esclera ${ }^{24}$. Adicionalmente, a avaliação do nervo óptico e o exame de campo visual podem ser limitados pelo diâmetro da zona óptica, assim como pelo possível surgimento da membrana retroprotética, ou pela dificuldade de fixação ${ }^{24}$. A avaliação angular com gonioscopia também não pode ser realizada pela opacidade da córnea periférica, apesar de estudos com tomografia de coerência óptica de segmento anterior terem demonstrado que 0 fechamento angular progressivo é um dos grandes contribuintes para desenvolvimento e progressão do glaucoma $24,57,58$.

\subsection{Aniridia}

A aniridia é uma doença congênita, fenotipicamente heterogênea, rara, de acometimento bilateral com envolvimento de múltiplas estruturas oculares e possui, como característica marcante, a ausência parcial ou 
quase completa de íris ${ }^{6}$. Com raras exceções, estas alterações são 0 resultado da haploinsuficiência do gene PAX 6 no cromossomo $11^{1,2}$.

Esta complexa afecção ocular manifesta-se em um espectro de disgenesia do segmento anterior, hipoplasia foveal, hipoplasia do nervo óptico, catarata pré-senil, glaucoma e ceratopatia ${ }^{2,3,5,6}$. A acuidade visual é variável, geralmente reduzida a menos de 20/100 e acompanhada de nistagmo e sobretudo, atribuída à hipoplasia foveal ${ }^{2,3,5}$.

Nessa doença, a maioria dos portadores (50\% a $85 \%$ ) irá desenvolver catarata no final da adolescência e início da vida adulta, o que poderá ocasionar perda significativa da acuidade visual ${ }^{3}$.

O glaucoma é uma manifestação comum, acomete metade dos pacientes, também no final da adolescência, pelo mecanismo atribuído ao fechamento angular sinequial por rotação anterior do coto da íris rudimentar, embora outros mecanismos, como a disgenesia do canal de Schlemm também tenham sido sugeridos ${ }^{3,5,7,8}$.

O diagnóstico e o acompanhamento podem ser desafiadores com 0 desenvolvimento da opacidade na córnea. No cuidado desses pacientes, deve-se atentar para a medida da espessura central da córnea que, geralmente, está aumentada (> $630 \mu \mathrm{m})$, o que altera a interpretação da medida da $\mathrm{PIO}{ }^{59}$. A goniotomia profilática pode ser realizada na tentativa de prevenção e retardo do surgimento do glaucoma ${ }^{7}$. A terapia medicamentosa é, com frequência, ineficaz no controle do glaucoma associado à aniridia ${ }^{8}$. 0 tratamento cirúrgico também é desafiador, com resultados mais favoráveis relatados com implantes de drenagem para glaucoma ${ }^{60-62}$. 


\subsection{Ceratopatia associada à aniridia}

Ao nascimento, a córnea é transparente, porém, no início da adolescência, a ceratopatia manifesta-se com a vascularização do epitélio periférico e espessamento, que avança gradativamente até o acometimento da córnea central, com possível progressão para fibrose subepitelial e cicatrização profunda estromal 9, 11. A ceratopatia pode levar a várias complicações, incluindo erosões recorrentes, olho seco, ulceração, dor crônica, neovascularização e redução progressiva da $A \bigvee$ 63, 64 .

Embora ainda não sejam claramente entendidos, o desenvolvimento e a progressão da ceratopatia são sobretudo atribuídos a uma disfunção das células tronco limbares e a um microambiente regulador comprometido pelos efeitos das mutações do PAX6 ${ }^{65,66}$. Este gene desempenha um papel fundamental na regulação da expressão das citoqueratinas 12 e 3 , constituintes dos filamentos intermediários do citoesqueleto epitelial, cujos níveis reduzidos estão associados à fragilidade epitelial, clinicamente manifestada por defeitos epiteliais persistentes ${ }^{67,68}$. O gene PAX6 também regula o metabolismo da metaloproteinase 9 , cuja deficiência altera a remodelação da matrix extracelular e causa o acúmulo de fibrina, infiltração de células inflamatórias e, consequente, opacidade de córnea ${ }^{66,69}$. Estudos histopatológicos, citológicos e clínicos correlacionam a progressão da disfunção das células tronco limbares com a perda da paliçada de Vogt, "conjuntivalização" da córnea, redução da inervação periférica e invasão de células caliciformes e inflamatórias $9,67,70$. 
O manejo terapêutico desses pacientes dependerá do grau de comprometimento da superfície ocular. Na maioria dos casos, pacientes com ceratopatia leve, o tratamento com lubrificantes, lentes de contato terapêuticas, tarsorrafia pode ser suficiente para melhora da superfície ocular 63. Em pacientes com ceratopatia moderada, com recorrente ulceração e início de fibrose subepitelial, o soro autólogo e o transplante de membrana amniótica podem aumentar a sobrevida de células-tronco límbicas, embora sejam medidas temporárias ${ }^{63}$.

A ceratopatia avançada, com comprometimento visual por cicatriz estromal e "conjuntivalização" da córnea central, requer o tratamento para restituição de um eixo visual sem opacidade ${ }^{63}$. O transplante penetrante isolado tem uma taxa de sucesso limitada por não tratar a disfunção límbica subjacente, o que resulta em alto índice de falência ${ }^{12,13}$. Técnicas de transplante limbares, como o transplante alógeno ceratolímbico de doador cadáver com a possibilidade de subsequente ceratoplastia penetrante para reabilitação visual, requerem o uso de imunossupressão para a prevenção de rejeição, altamente comum em pacientes jovens e não complacentes à terapia imunossupressora 10, 14, 15, 71 . 
4 Métodos 


\section{MÉTODOS}

\subsection{Aspectos éticos}

Trata-se de um estudo retrospectivo com análise de prontuários aprovado pelo Comitê de Estudos Humanos do Conselho de Revisão Institucional (Institutional Review Board, IRB) do hospital Massachusetts Eye and Ear, Boston, Estados Unidos da América - protocolo 1097135-1/17103H (Anexo 1). O estudo também foi aprovado pela Comissão de Ética em Pesquisa da Faculdade de Medicina da Universidade de São Paulo, sob o número CAAE 80486017.6.0000.0065 (Anexo 2).

\subsection{Desenho do estudo}

Esta é uma revisão retrospectiva de prontuários de pacientes que foram submetidos ao implante da B-KPro tipo 1 com placa posterior de titânio realizada por três cirurgiões no hospital Massachusetts Eye and Ear, Boston, Estados Unidos da América, entre outubro de 2007 e dezembro de 2015.

Os casos do estudo foram divididos em dois grupos, conforme a indicação para cirurgia da B-KPro tipo 1. Todos os pacientes com ceratopatia associada à aniridia, submetidos à cirurgia da B-KPro tipo 1 
durante o período de tempo alocado, foram incluídos. O grupo comparativo foi composto por todos os indivíduos adultos com outros diagnósticos préoperatórios, excluindo pacientes com distúrbios oculares congênitos, pelo potencial confundidor da ambliopia para análise de acuidade visual, com síndrome de Stevens-Johnson ou penfigoide ocular cicatricial, por serem afecções oculares associadas a um alto grau de complicações com a B-KPro tipo 1 de Boston, normalmente, são tratadas com implante B-KPro tipo 240 . Para o estudo, um olho por paciente foi selecionado por critério baseado no maior tempo de seguimento.

A fim de relatar resultados intermediários e de longo prazo, os pacientes com menos de 2 anos de acompanhamento após o implante de BKPro foram excluídos. Olhos, em que o nervo óptico não pôde ser visualizado ou a relação escavação-/disco (E/D) não foi definida por palidez de disco, foram excluídos de todas as análises de desfechos relacionados ao glaucoma (Tabela 6) e na análise de Kaplan-Meier (Figuras 2, 3, 4,e 5).

\subsection{Coleta de dados}

Os dados pré-operatórios e pós-operatórios foram coletados dos prontuários clínicos dos especialistas em córnea e glaucoma até fevereiro de 2018. Muitos pacientes foram encaminhados de outros serviços, e as informações das cartas de referência também foram avaliadas. Adicionalmente, foram coletados dados perioperatórios de relatórios 
cirúrgicos do implante da B-KPro tipo 1 e das cirurgias de glaucoma realizadas concomitante ou posteriormente ao implante dessa prótese.

A PIO foi determinada no pré-operatório pela tonometria de aplanação de Goldmann ou Tonopen (Reichert, Depew, Nova York, Estados Unidos da América) e no pós-operatório pela medida digital dos especialistas em córnea e/ou glaucoma. A média foi calculada quando a medida digital foi registrada em um intervalo.

\subsection{Critérios para definição de glaucoma preexistente}

O glaucoma preexistente foi definido como um diagnóstico documentado de glaucoma, uso de medicação para redução da PIO ou histórico de cirurgia de glaucoma antes do implante da ceratoprótese. Em razão da opacidade severa da córnea antes da cirurgia B-KPro tipo 1, a avaliação pré-operatória do nervo óptico e o teste de campo visual não foram realizados na maioria dos pacientes.

\subsection{Critérios para definição de progressão e diagnóstico de glaucoma}

Para a avaliação da progressão e do diagnóstico de glaucoma após o implante da ceratoprótese, foram definidos como o aumento $\geq 0,2$ na relação E/D observada no exame oftalmoscópico pelo mesmo especialista em córnea ou glaucoma. Os critérios baseados em imagem do nervo óptico ou campo visual também não foram considerados neste estudo pela alta 
prevalência de hipoplasia foveal e nistagmo no grupo aniridia, limitadores da qualidade e da reprodutibilidade destes exames.

\subsection{Medidas da acuidade visual}

A AV corrigida com notação em Snellen foi convertida no logaritmo do ângulo mínimo de resolução (logarithm of the Minimum Angle of Resolution, logMAR). Para um AV inferior a 20/400, as equivalências em logMAR foram as seguintes: contagem de dedos $(C D)=1,98$; movimentos da mão $(M M)=2,28$; percepção luminosa $(P L)=2,8072,73$. O registro de sem percepção luminosa (SPL) foi convertido a um valor de $2,9^{74}$. A melhora da AV foi considerada quando a medida no último seguimento foi melhor que a pré-operatória.

\subsection{Complicações de alto risco}

As seguintes complicações pós implante foram registradas e consideradas de alto risco, por serem potenciais causas de extrusão ou substituição de ceratoprótese, com possível comprometimento visual irreversível: ceratite infecciosa, necrose estromal, vitreíte não infecciosa, endoftalmite, hemorragia vítrea, descolamento de retina, hipotonia resultante em descolamento coroide ou hemorragia supracoroidiana 75,76 . 


\subsection{Análise estatística}

A análise estatística foi realizada com o software comercial (Stata versão 15.1; StataCorp, College Station, Texas, Estados Unidos da América). O teste de Shapiro-Wilk foi utilizado para testar a distribuição normal das variáveis contínuas; o teste t de Student bicaudal, para comparar as variáveis contínuas normalmente distribuídas; o teste Wilcoxon, para comparar variáveis não paramétricas e o teste Qui-quadrado de Pearson para comparar as variáveis categóricas. As variáveis quantitativas foram expressas como média \pm desvio-padrão (DP) e as qualitativas foram expressas como porcentagens. A análise de sobrevida de Kaplan-Meier foi usada para comparar a retenção da acuidade visual melhor que PL e melhor ou igual a 20/200. Esta análise foi realizada também para retenção de uma relação E/D menor ou igual a 0,8, e manutenção de uma progressão menor que 0,2 . O teste de log-rank foi usado para as comparações de grupos nas análises de Kaplan-Meier. Adotou-se como nível de significância estatística o valor de $p<0,05$. 


\section{RESULTADOS}

A fim de relatar resultados intermediários e de longo prazo, os pacientes com menos de 2 anos de acompanhamento após o implante da BKPro tipo 1 foram excluídos. Entretanto, conforme as diretrizes propostas pelo Keratoprosthesis Study Group (Barcelona, 2015) para relatar os resultados relacionados a essa prótese, todas os casos de falha de retenção, incluindo o período excludente de 2 anos, foram reportados nos dados da Tabela $1{ }^{77}$. 
Tabela 1 - Características dos olhos submetidos à ceratoprótese de Boston tipo 1 com falência de retenção ou phthisis dentro, de 2 anos após a cirurgia

\begin{tabular}{|c|c|c|c|c|c|}
\hline Indicação & $\begin{array}{l}\text { Pré } \\
\text { AV }\end{array}$ & $\begin{array}{l}\text { Pós } \\
\text { AV }\end{array}$ & $\begin{array}{l}\text { Meses } \\
\text { para } \\
\text { falência }\end{array}$ & $\begin{array}{l}\text { Causa da } \\
\text { falência }\end{array}$ & Informações adicionais \\
\hline Ceratocone & CD & MM & 22,3 & $\begin{array}{l}\text { Extrusão por } \\
\text { necrose } \\
\text { estromal }\end{array}$ & $\begin{array}{l}\text { Extrusão por necrose estromal } \\
\text { tratada com transplante } \\
\text { penetrante. }\end{array}$ \\
\hline $\begin{array}{l}\text { Distrofia } \\
\text { endotelial de } \\
\text { Fuchs }\end{array}$ & MM & MM & 19,3 & $\begin{array}{l}\text { Extrusão por } \\
\text { ceratite } \\
\text { infecciosa }\end{array}$ & $\begin{array}{l}\text { Ceratite infecciosa causada por } \\
\text { Streptococcus pneumoniae após } \\
12 \text { meses do implante tratada } \\
\text { com explante da B-KPro tipo } 1 .\end{array}$ \\
\hline $\begin{array}{l}\text { Trauma } \\
\text { penetrante }\end{array}$ & PL & PL & 12,1 & Phthisis & $\begin{array}{l}\text { Vitrectomia prévia para } \\
\text { tratamento de hemorragia vítrea e } \\
\text { descolamento de retina. }\end{array}$ \\
\hline $\begin{array}{l}\text { Trauma } \\
\text { penetrante }\end{array}$ & CD & MM & 8,3 & Phthisis & $\begin{array}{l}\text { Prévia história de hipotonia e } \\
\text { ambliopia. }\end{array}$ \\
\hline $\begin{array}{l}\text { Úlcera } \\
\text { neurotrófica }\end{array}$ & MM & PL & 19,9 & $\begin{array}{l}\text { Extrusão por } \\
\text { necrose } \\
\text { estromal }\end{array}$ & $\begin{array}{l}\text { Extrusão por necrose estromal } \\
\text { tratada com transplante } \\
\text { penetrante e tarsorrafia. }\end{array}$ \\
\hline $\begin{array}{l}\text { Úlcera } \\
\text { neurotrófica }\end{array}$ & MM & PL & 17,6 & $\begin{array}{l}\text { Extrusão por } \\
\text { necrose } \\
\text { estromal }\end{array}$ & $\begin{array}{l}\text { Necrose estromal tratada com } \\
\text { ceratoplastia lamelar e tarsorrafia } \\
\text { após } 5 \text { meses do implante. } \\
\text { Extrusão por necrose estromal } \\
\text { recorrente tratada com } \\
\text { substituição da B-KPro tipo } 1 \\
\text { em14 meses. Segunda extrusão } \\
\text { por necrose estromal tratada com } \\
\text { transplante penetrante em } 17 \\
\text { meses. }\end{array}$ \\
\hline
\end{tabular}

NOTAS: Todos os olhos por falha na retenção ou phthisis pertencem ao grupo comparativo. $\mathrm{AV}$ = acuidade visual; $\mathrm{CD}$ : conta dedos; $\mathrm{MM}$ = movimento de mãos; $\mathrm{PL}$ = percepção luminosa. 
Este estudo incluiu 83 olhos, 22 olhos com aniridia, e 61 olhos com outros diagnósticos inclusos no grupo comparativo submetidos ao implante da B-KPro tipo 1. Todos os olhos com aniridia apresentaram ceratopatia avançada com comprometimento visual. As indicações para o implante da BKPro tipo 1 no grupo comparativo, como tratamento cirúrgico primário ou como tratamento cirúrgico após a falência do transplante de córnea, estão descritas nos dados da Tabela 2.

Tabela 2 - Número de casos por indicação da ceratoprótese de Boston (BKPro) tipo 1 no grupo comparativo

\begin{tabular}{|c|c|c|}
\hline & $\begin{array}{l}\text { B-KPro tipo } 1 \\
\text { como tratamento } \\
\text { cirúrgico } \\
\text { primário }\end{array}$ & $\begin{array}{l}\text { B-KPro tipo } 1 \text { como } \\
\text { tratamento cirúrgico } \\
\text { após a falência do } \\
\text { transplante de córnea }\end{array}$ \\
\hline \multicolumn{3}{|l|}{ Não inflamatória } \\
\hline Ceratopatia bolhosa do pseudofácico & $3(4,9 \%)$ & $6(9,8 \%)$ \\
\hline Distrofia endotelial de Fuchs & $0(0 \%)$ & $6(9,8 \%)$ \\
\hline Ceratocone & $1(1,6 \%)$ & $3(4,9 \%)$ \\
\hline Trauma penetrante & $3(4,9 \%)$ & $3(4,9 \%)$ \\
\hline Úlcera neurotrófica & $5(8,2 \%)$ & $1(1,6 \%)$ \\
\hline Ceratopatia por óleo de silicone & $3(4,9 \%)$ & $1(1,6 \%)$ \\
\hline Degeneração nodular de Salzmann & $1(1,6 \%)$ & $0(0 \%)$ \\
\hline Cicatriz de causa desconhecida & $1(1,6 \%)$ & $0(0 \%)$ \\
\hline Ceratoconjuntivite atópica & $1(1,6 \%)$ & $0(0 \%)$ \\
\hline \multicolumn{3}{|l|}{ Inflamatória/ infecciosa } \\
\hline Ceratite fúngica, bacteriana ou parasitária & $5(8,2 \%)$ & $5(8,2 \%)$ \\
\hline Ceratite herpética & $2(3,3 \%)$ & $2(3,3 \%)$ \\
\hline Ceratite interticial & $1(1,6 \%)$ & $0(0 \%)$ \\
\hline Úlcera de Mooren & $1(1,6 \%)$ & $0(0 \%)$ \\
\hline \multicolumn{3}{|l|}{ Queimadura } \\
\hline Química & $2(3,3 \%)$ & $2(3,3 \%)$ \\
\hline Térmica & $1(1,6 \%)$ & $2(3,3 \%)$ \\
\hline
\end{tabular}

NOTA: Dados foram apresentados como o número de olhos (porcentagem de olhos em um total de 61 olhos no grupo comparativo). 
5.1 Dados demográficos, pré-operatórios, perioperatórios, pósoperatórios e resultados visuais

A média de idade no momento da cirurgia foi significativamente menor para o grupo aniridia (46,7 $\pm 13,2$ anos) do que o grupo comparativo $(61,9 \pm$ 15,6 anos; $p<0,001 ;$ Tabela 3). Não se observou diferença significativa entre os grupos em relação ao gênero $(p=0,24)$ e raça $(p=0,23)$. $O$ tempo médio de seguimento foi $70,7 \pm 28,6$ meses para o grupo aniridia, e $63,8 \pm$ 25,5 meses para o grupo comparativo $(p=0,25)$. 
Tabela 3 - Dados demográficos, pré-operatórios, perioperatórios, pósoperatórios e resultados visuais relacionados ao implante da ceratoprótese

\begin{tabular}{|c|c|c|c|}
\hline Dados & $\begin{array}{l}\text { Grupo Aniridia } \\
\text { n=22 olhos }\end{array}$ & $\begin{array}{c}\text { Grupo } \\
\text { Comparativo } \\
\mathrm{n}=61 \text { olhos }\end{array}$ & $\mathbf{p}$ \\
\hline \multicolumn{4}{|l|}{ Demográficos e tempo de seguimento } \\
\hline $\begin{array}{l}\text { Idade ao realizar a cirurgia de B-KPro } \\
\text { tipo } 1 \text {, anos }\end{array}$ & $46,7 \pm 13,2$ & $61,9 \pm 15,6$ & $<0,001$ \\
\hline Gênero, masculino & $8(36,4 \%)$ & $31(50,8 \%)$ & 0,24 \\
\hline Raça, brancos & $19(86,4 \%)$ & $45(73,8 \%)$ & 0,23 \\
\hline Tempo de seguimento, meses & $70,7 \pm 28,6$ & $63,8 \pm 25,5$ & 0,25 \\
\hline \multicolumn{4}{|l|}{ Pré-operatórios } \\
\hline AV corrigida, logMAR & $1,85 \pm 0,35$ & $1,87 \pm 0,57$ & 0,33 \\
\hline AV corrigida $<20 / 200$ & $21(95,5 \%)$ & $51(83,6 \%)$ & 0,16 \\
\hline Falência do transplante de córnea prévio & $5(22,7 \%)$ & $31(50,8 \%)$ & 0,02 \\
\hline \multicolumn{4}{|l|}{ Status da lente/cristalino } \\
\hline Afácico & $4(18,2 \%)$ & $13(21,3 \%)$ & 0,76 \\
\hline Fácico & $12(54,5 \%)$ & $18(29,5 \%)$ & 0,04 \\
\hline Pseudofácico & $6(27,3 \%)$ & $30(49,2 \%)$ & 0,08 \\
\hline \multicolumn{4}{|l|}{ Perioperatórios } \\
\hline Tamanho da córnea receptora (mm) & $8,0 \pm 0,4$ & $8,2 \pm 0,5$ & 0,18 \\
\hline Tamanho da córnea doadora (mm) & $8,5 \pm 0,4$ & $8,7 \pm 0,5$ & 0,18 \\
\hline \multicolumn{4}{|l|}{ Tamanho da placa posterior * } \\
\hline $7 \mathrm{~mm}$ & $4 / 19(21,1 \%)$ & $6 / 55(10,9 \%)$ & 0,27 \\
\hline $8,5 \mathrm{~mm}$ & $13 / 19(68,4 \%)$ & $44 / 55(80,0 \%)$ & 0,30 \\
\hline $9,5 \mathrm{~mm}$ & $2 / 19(10,5 \%)$ & $5 / 55(9,1 \%)$ & 0,85 \\
\hline Remoção do cristalino & $12(54,5 \%)$ & $18(29,5 \%)$ & 0,04 \\
\hline Remoção da lente intraocular & $3(13,6 \%)$ & $11(18,0 \%)$ & 0,64 \\
\hline \multicolumn{4}{|l|}{ Pós-operatórios (no último seguimento) } \\
\hline AV corrigida, logMAR & $1,28 \pm 0,79$ & $1,23 \pm 0,98$ & 0,51 \\
\hline AV corrigida $<20 / 200$ & $9(40,9 \%)$ & $28(45,9 \%)$ & 0,69 \\
\hline $\begin{array}{l}\text { AV percepção luminosa ou sem } \\
\text { percepção luminosa }\end{array}$ & $3(13,6 \%)$ & $9(14,8 \%)$ & 0,90 \\
\hline $\begin{array}{l}\text { AV corrigida melhor que a medida pré- } \\
\text { operatória }\end{array}$ & $16(72,7 \%)$ & $44(72,1 \%)$ & 0,96 \\
\hline $\begin{array}{l}\text { AV corrigida pior que a medida pré- } \\
\text { operatória }\end{array}$ & $4(18,2 \%)$ & $14(23,0 \%)$ & 0,64 \\
\hline
\end{tabular}

NOTAS: As variáveis quantitativas foram expressas como média \pm desvio padrão e as qualitativas foram expressas como número de olhos (porcentagem).

*Dados disponíveis para 19 olhos no grupo aniridia e 55 olhos no grupo comparativo.

$\mathrm{B}-\mathrm{KPro}=$ ceratoprótese Boston; $\mathrm{AV}$ = acuidade visual; logMAR = logaritmo do ângulo mínimo de resolução. 
No pré-operatório, os grupos aniridia e comparativo tiveram a média da AV corrigida(1,85 $\pm 0,35 \log M A R, 1,87 \pm 0,57 \log M A R, p=0,33$, Tabela 3) e a porcentagem de olhos com AV corrigida < 20/200 (95,5\%, 83,6\%, $p=0,16)$ semelhantes. Mas, diferiram na porcentagem de olhos fácicos antes da cirurgia $(54,5 \%$ e $29,5 \%, p=0,04)$. O grupo aniridia apresentou um menor percentual de olhos com falência do transplante de córnea prévio $(22,7 \%)$ que o grupo comparativo $(50,8 \%, p=0,02)$.

No perioperatório, todas as córneas doadoras foram trepanadas, confeccionando um botão $0,5 \mathrm{~mm}$ maior que a trepanação no leito receptor. Não houve diferenças significativas nos diâmetros de trepanação das córneas do leito receptor e das córneas doadoras entre os grupos aniridia e comparativo $(8,0 \pm 0,4 \mathrm{~mm}$ vs. $8,2 \pm 0,5 \mathrm{~mm}, \mathrm{p}=0,18$; e $8,5 \pm 0,4 \mathrm{~mm}$ vs. $8,7 \pm 0,5 \mathrm{~mm}, \mathrm{p}=0,18$, respectivamente, Tabela 3$)$. Os grupos tiveram uma distribuição semelhante de tamanho das placas posteriores $(21,1 \%$ vs. $10.9 \%$ para $7,0 \mathrm{~mm}, \mathrm{p}=0,27 ; 68,4 \%$ vs. $80,0 \%$ para $8,5 \mathrm{~mm}, \mathrm{p}=0,30 ; \mathrm{e}$ $10,5 \%$ vs. $9,1 \%$ para $9,5 \mathrm{~mm}, \mathrm{p}=0,85)$. Os grupos aniridia e comparativo diferiram na porcentagem de olhos com remoção do cristalino concomitante à cirurgia $(54,5 \%$ e $29,5 \%, p=0,04)$, mas não diferiram no percentual de olhos com remoção de lente intraocular $(13,6 \%$ e $18,0 \%, p=0,64)$. Imediatamente, após o implante, $63,6 \%$ do grupo aniridia e 47,5\% do grupo comparativo ficaram afácicos $(p=0,20)$.

Na última consulta de seguimento do estudo, os grupos aniridia e comparativo tiveram AV corrigida semelhante $(1,28 \pm 0,79$ logMAR, $1,23 \pm 0,98 \log M A R, p=0,51)$. No grupo aniridia, $72,7 \%$ dos olhos 
apresentaram melhora na AV, enquanto $18,2 \%$ apresentaram piora quando comparados às respectivas AV corrigidas do pré-operatório. As distribuições percentuais foram semelhantes ao grupo comparativo $(72,1 \%$ melhoraram, $p=0,96$ e $23,0 \%$ pioraram, $p=0,64)$. Adicionalmente, ambos os grupos apresentaram porcentagens similares de olhos com AV corrigida pior que $20 / 200(40,9 \%$ e $45,9 \%, p=0,69)$ e com AV de PL ou SPL $(13,6 \%$ e $14,8 \%$, $p=0,90)$. A AV pós-operatória foi limitada sobretudo por hipoplasia foveal e glaucoma na maioria dos olhos com aniridia (Tabela 4). Três olhos no grupo aniridia evoluíram com AV final $\mathrm{PL}$, dois casos relacionados ao descolamento de retina, e um à efusão de coroide secundária à hipotonia. No grupo aniridia, nenhum olho teve a AV final SPL na última consulta de seguimento do estudo. As principais causas potenciais para uma AV final PL ou SPL no grupo comparativo foram glaucoma e afecções retinianas. No seguimento final, 8 dos 22 olhos com aniridia (36,4\%) e 21 de 61 (34,4\%) dos olhos apresentaram membranas retroprotéticas, que foram observados ou tratados a critério do especialista em córnea. 


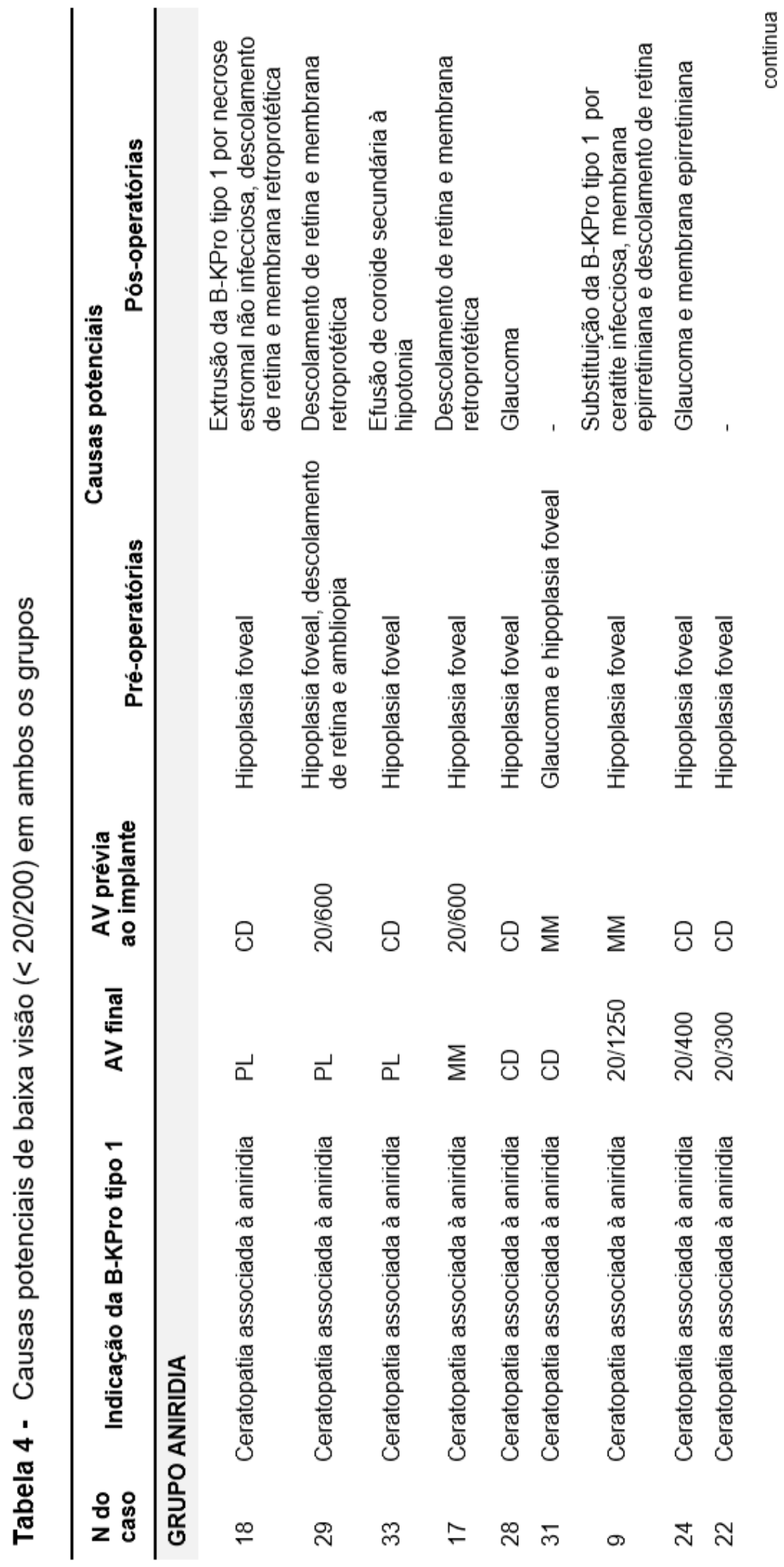




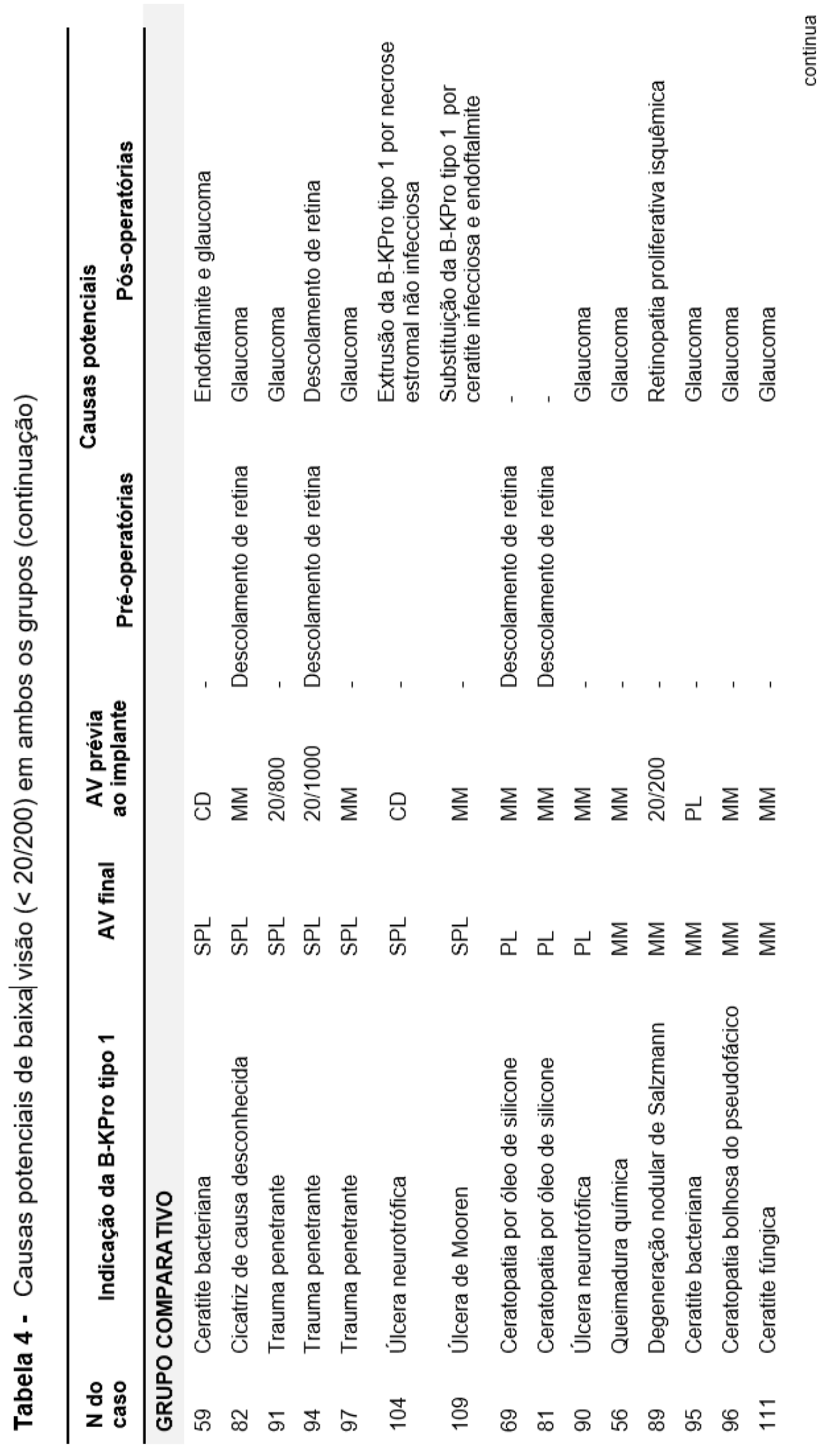




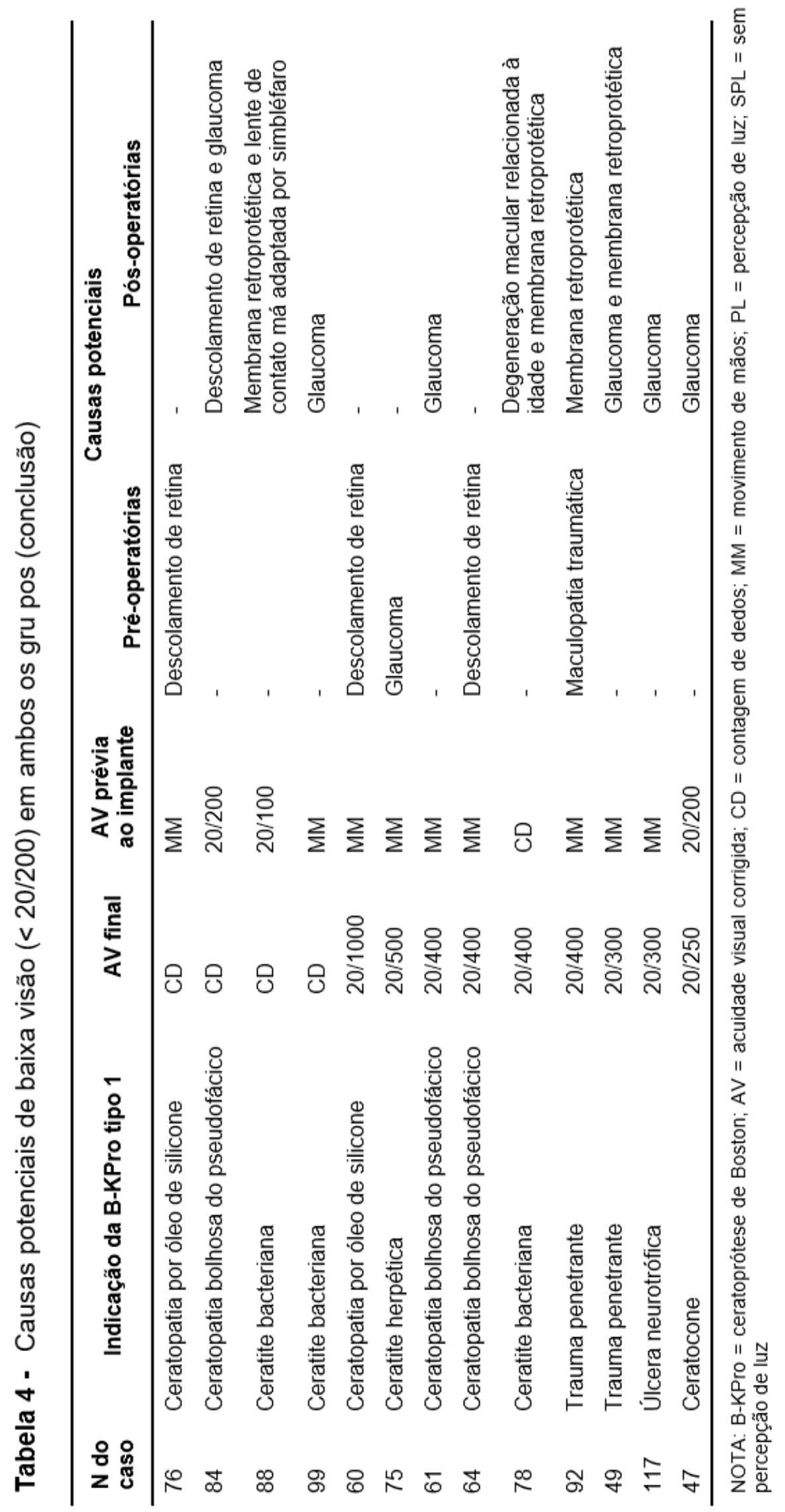


A análise comparativa da melhor AV corrigida no último dia de seguimento comparada com a medida pré-operatória por indicação está apresentada nos dados da Tabela 5. As etiologias que apresentaram melhora estatisticamente significativa da AV foram ceratopatia associada à aniridia $(p=0,003)$, ceratopatia bolhosa do pseudofácico $(p=0,01)$ e distrofia endotelial de Fuchs $(p=0,005)$.

Tabela 5 - A análise comparativa da acuidade visual final com a medida pré-operatória por indicação

\begin{tabular}{|c|c|c|c|c|c|}
\hline Indicação & $\mathbf{n}$ & $\begin{array}{c}\text { AV pré } \\
\text { logMAR, } \\
\text { média } \pm \text { DP }\end{array}$ & $\begin{array}{c}\text { AV pós } \\
\text { logMAR, } \\
\text { média } \pm \text { DP }\end{array}$ & $\begin{array}{l}\text { Conversão } \\
\text { em Snellen }\end{array}$ & $\mathbf{p}$ \\
\hline \multicolumn{6}{|l|}{ Não inflamatória } \\
\hline $\begin{array}{l}\text { Ceratopatia associada à } \\
\text { aniridia }\end{array}$ & 22 & $1,85 \pm 0,35$ & $1,28 \pm 0,79$ & $20 / 381$ & 0,003 \\
\hline $\begin{array}{l}\text { Ceratopatia bolhosa do } \\
\text { pseudofácico }\end{array}$ & 9 & $1,96 \pm 0,48$ & $1,15 \pm 0,63$ & $20 / 283$ & 0,01 \\
\hline Distrofia endotelial de Fuchs & 6 & $1,43 \pm 0,52$ & $0,25 \pm 0,23$ & $20 / 36$ & 0,005 \\
\hline Ceratocone & 4 & $1,57 \pm 0,66$ & $0,69 \pm 0,40$ & $20 / 98$ & 0,08 \\
\hline Trauma penetrante & 6 & $2,02 \pm 0,31$ & $1,88 \pm 0,49$ & $20 / 1517$ & 1,00 \\
\hline Úlcera neurotrófica & 6 & $1,54 \pm 0,72$ & $1,36 \pm 1,20$ & $20 / 458$ & 0,69 \\
\hline $\begin{array}{l}\text { Ceratopatia por óleo de } \\
\text { silicone }\end{array}$ & 4 & $2,28^{*} \pm 0$ & $2,32 \pm 0,57$ & $20 / 4179$ & 1,00 \\
\hline $\begin{array}{l}\text { Degeneração nodular de } \\
\text { Salzmann }\end{array}$ & 1 & 1 & $2,28^{*}$ & $20 / 3811$ & ND \\
\hline $\begin{array}{l}\text { Cicatriz de causa } \\
\text { desconhecida }\end{array}$ & 1 & $2,28^{*}$ & $2,9^{*}$ & 20/15887 & ND \\
\hline Ceratoconjuntivite atópica & 1 & $2,28^{*}$ & 0,1 & $20 / 25$ & ND \\
\hline \multicolumn{6}{|l|}{ Inflamatória/ infecciosa } \\
\hline $\begin{array}{l}\text { Ceratite fúngica, bacteriana } \\
\text { ou parasitária }\end{array}$ & 10 & $2,14 \pm 0,59$ & $1,50 \pm 0,90$ & $20 / 632$ & 0,10 \\
\hline Ceratite herpética & 4 & $1,74 \pm 0,70$ & $0,77 \pm 0.50$ & $20 / 118$ & 0,11 \\
\hline Ceratite intersticial & 1 & 1,3 & 0,88 & $20 / 152$ & ND \\
\hline Úlcera de Mooren & 1 & $2,28^{*}$ & $2,9^{\star}$ & 20/15887 & ND \\
\hline \multicolumn{6}{|l|}{ Queimadura } \\
\hline Química & 4 & $1,91 \pm 0,37$ & $0,79 \pm 1,06$ & $20 / 123$ & 0,19 \\
\hline Térmica & 3 & $1,93 \pm 0,90$ & $0,45 \pm 0,05$ & $20 / 56$ & 0,05 \\
\hline
\end{tabular}


A análise de Kaplan-Meier demonstra que tanto a aniridia como o grupo comparativo tiveram probabilidades similares ao longo do tempo em reter um AV melhor do que PL ( $p=0,36$, Figura 2) e melhor 20/200 $(p=0,71$, Figura 3)

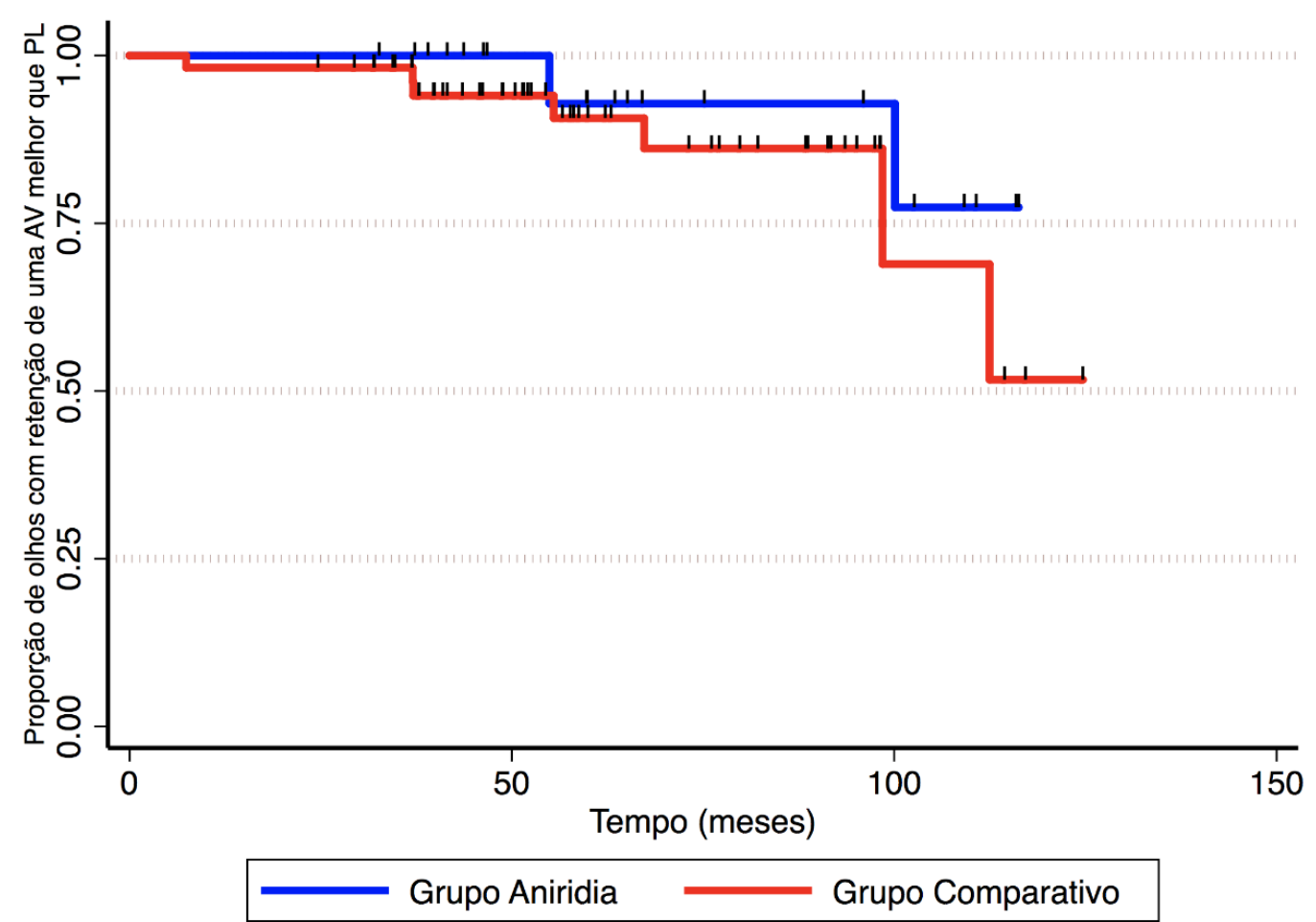

Figura 2 - Acuidade visual melhor que a percepção luminosa (PL) após cirurgia de ceratoprótese tipo 1 de Boston nos grupos aniridia e comparativo. As curvas de Kaplan-Meier comparam a proporção de olhos nos grupos aniridia (linha azul) e comparativo (linha vermelha) ao longo do tempo que retiveram uma melhor acuidade visual corrigida melhor que PL. Ambos os grupos apresentaram similar taxa de retenção $(p=0,36$, teste de log-rank) 


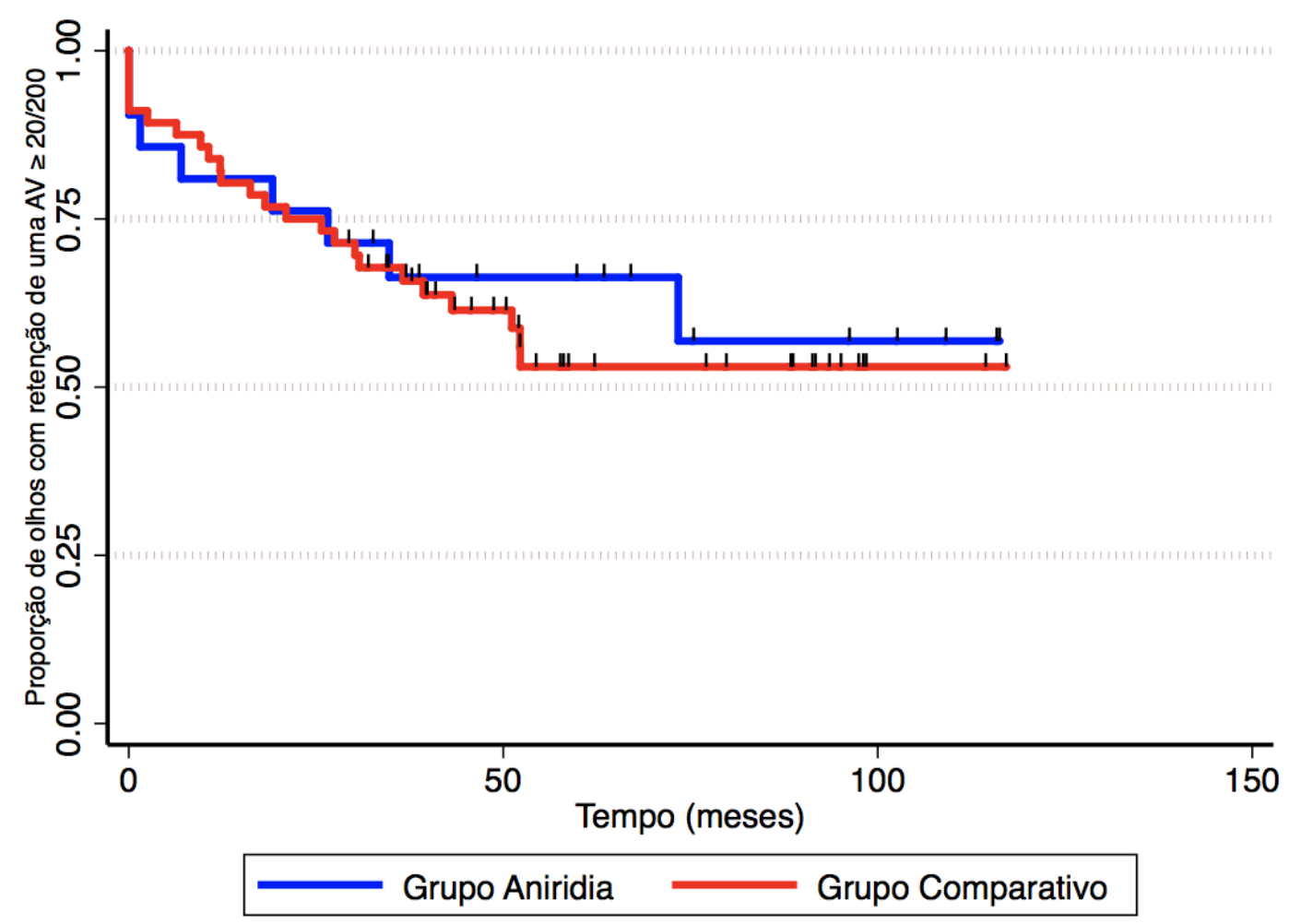

Figura 3 - Acuidade visual melhor ou igual a 20/200 após cirurgia de ceratoprótese tipo 1 de Boston nos grupos aniridia e comparativo. As curvas de Kaplan-Meier comparam a proporção de olhos nos grupos aniridia (linha azul) e comparativo (linha vermelha) ao longo do tempo que retiveram uma melhor acuidade visual corrigida melhor ou igual a 20/200. Ambos os grupos apresentaram similar taxa de retenção $(p=0,71$, teste de log-rank) 


\subsection{Resultados relacionados ao glaucoma}

No grupo aniridia, 21 olhos (95,5\%) e 56 (91,8\%) no grupo comparativo foram incluídos nessa análise relacionada ao glaucoma (Tabela 6). Um olho do grupo aniridia e cinco olhos do grupo comparativo foram excluídos da análise em razão da impossibilidade de visualização do nervo óptico ou determinação da relação E/D por palidez significativa secundária à doença da retina. Antes da cirurgia de implante da B-KPro tipo 1, mais olhos no grupo aniridia tinham o diagnóstico de glaucoma $(76,2 \%)$ e uma história de cirurgia de glaucoma $(57,1 \%)$ em comparação ao segundo grupo $(51,8 \%$, $p=0,053 ; 23,2 \%, p=0,005$, respectivamente). Durante a cirurgia de B-KPro tipo 1, uma proporção maior de olhos com aniridia $(47,6 \%)$ realizou o implante concomitante de tubo de drenagem de glaucoma comparado com os $17,9 \%$ de proporção do grupo comparativo $(p=0,008)$. A cirurgia profilática de tubo, considerada como o implante concomitante à cirurgia de B-KPro tipo 1 em olhos sem glaucoma preexistente, foi realizada em dois entre os 5 pacientes sem o diagnóstico de glaucoma $(40,0 \%)$ no grupo aniridia e dois entre os $27(7,4 \%)$ no grupo comparativo $(p=0,04)$. Todos os implantes de drenagem neste estudo foram do tipo Ahmed (New World Medical Inc., Rancho Cucamonga, Califórnia, Estados Unidos da América), com a exceção de três casos implantados antes da cirurgia de B-KPro tipo 1 com o tipo Baerveldt (Abbott Medical Optics, Inc., Santa Ana, Califórnia, Estados Unidos da América) ou o tipo Molteno (Molteno Ophthalmic Limited, Dunedin, Nova Zelândia). 
Tabela 6 - Dados dos grupos relacionados ao glaucoma

\begin{tabular}{|c|c|c|c|}
\hline Dados & $\begin{array}{l}\text { Grupo Aniridia } \\
n=21 \text { olhos }\end{array}$ & $\begin{array}{c}\text { Grupo } \\
\text { Comparativo } \\
n=56 \text { olhos }\end{array}$ & $\mathbf{p}$ \\
\hline \multicolumn{4}{|l|}{ Pré-operatórios } \\
\hline Pressão intraocular, mmHg * & $16,9 \pm 4,6$ & $15,3 \pm 5,6$ & 0,24 \\
\hline $\begin{array}{l}\text { Uso de medicação para redução da pressão } \\
\text { intraocular }\end{array}$ & $12(57,1 \%)$ & $25(44,6 \%)$ & 0,33 \\
\hline Diagnóstico de glaucoma & $16(76,2 \%)$ & $29(51,8 \%)$ & 0,053 \\
\hline Cirurgia de glaucoma prévia & $12(57,1 \%)$ & $13(23,2 \%)$ & 0,005 \\
\hline \multicolumn{4}{|l|}{ Perioperatórios } \\
\hline Implante concomitante do tubo de drenagem & $10(47,6 \%)$ & $10(17,9 \%)$ & 0,008 \\
\hline Implantando na câmara anterior & $8(38,1 \%)$ & $7(12,5 \%)$ & 0,01 \\
\hline Implantado na pars plana & $2(9,5 \%)$ & $3(5,4 \%)$ & 0,51 \\
\hline sem diagnóstico de glaucoma (profilático) & $2 / 5(40,0 \%)$ & $2 / 27(7,4 \%)$ & 0,04 \\
\hline \multicolumn{4}{|l|}{ Pós-operatórios no último seguimento } \\
\hline Pressão intraocular, mmHg & $12,4 \pm 5,3$ & $14,1 \pm 4,7$ & 0,19 \\
\hline $\begin{array}{l}\text { Uso de medicação para redução da pressão } \\
\text { intraocular }\end{array}$ & $15(71,4 \%)$ & $37(66,1 \%)$ & 0,66 \\
\hline Diagnóstico de glaucoma & $19(90,5 \%)$ & $36(64,3 \%)$ & 0,02 \\
\hline Implante do tubo de drenagem & $4(19,0 \%)$ & $5(8,9 \%)$ & 0,22 \\
\hline Procedimento ciclodestrutivo & $4(19,0 \%)$ & $12(21,4 \%)$ & 0,82 \\
\hline $\begin{array}{l}\text { Realização de, pelo menos, uma cirurgia de } \\
\text { glaucoma }\end{array}$ & $19(90,5 \%)$ & $30(53,6 \%)$ & 0,003 \\
\hline \multicolumn{4}{|l|}{ Resultados relacionados ao nervo óptico ** } \\
\hline$E / D>0.8$ & $5(23,8 \%)$ & $17(30,4 \%)$ & 0,57 \\
\hline Progressão da relação E/D $\geq 0.2$ & $9(42,9 \%)$ & $25(44,6 \%)$ & 0,89 \\
\hline $\begin{array}{l}\text { Progressão da relação } E / D \geq 0.2 \text { em olhos } \\
\text { com glaucoma preexistente }\end{array}$ & $6 / 16(37,5 \%)$ & $18 / 29(62,1 \%)$ & 0,11 \\
\hline $\begin{array}{l}\text { Progressão da relação } E / D \geq 0.2 \text { em olhos } \\
\text { sem glaucoma preexistente e sem implante } \\
\text { profilático }\end{array}$ & $3 / 3(100 \%)$ & $7 / 25(28,0 \%)$ & 0,01 \\
\hline $\begin{array}{l}\text { Progressão da relação } E / D \geq 0.2 \text { sem } \\
\text { glaucoma preexistente, mas com implante } \\
\text { profilático }\end{array}$ & $0 / 2(0 \%)$ & $0 / 2(0 \%)$ & ND \\
\hline
\end{tabular}

NOTAS: As variáveis quantitativas foram expressas como média \pm desvio-padrão e as qualitativas foram expressas como número de olhos (porcentagem). $O$ valor de $p$ não estará disponível se 0 número de olhos em ambos os grupos for menor que 2.

*Pressão intraocular não disponível em um paciente no grupo comparativo em razão da descemetocele.

${ }^{* *}$ Cada análise da progressão da relação $E / D \geq 0.2$ foi feita com base na última medida registrada após pelo menos 2 anos de acompanhamento.

$\mathrm{E} / \mathrm{D}=$ escavação-disco; ND = não disponível. 
No final do seguimento deste estudo, mais olhos no grupo de aniridia tiveram o diagnóstico de glaucoma $(90,5 \%)$ do que o grupo comparativo $(64,3 \%, p=0,02)$. Mas, os dois grupos apresentaram semelhantes médias da PIO $(12,4 \pm 5,3 \mathrm{mmHg}$ vs. $14,1 \pm 4,7 \mathrm{mmHg}, \mathrm{p}=0,19)$, proporções de olhos tratados com medicação para redução da $\mathrm{PIO}(71,4 \%$ vs. $66,1 \%$, $p=0,66)$ e proporções de olhos com cirurgia de glaucoma após o implante de B-KPro tipo 1 (19,0\% vs. 8,9\%, $p=0,22$; procedimento ciclodestrutivo: $19,0 \%$ vs. $21,4 \%, p=0,82$ ). Mais olhos no grupo aniridia foram submetidos a, pelo menos, uma cirurgia de glaucoma $(90,5 \%)$ antes, durante ou após o implante de B-KPro do que o grupo comparativo $(53,6 \%, p=0,003)$. Para análise do nervo óptico, as proporções de olhos com um aumento na relação $E / D \geq 0,2$ foram semelhantes nos dois grupos (aniridia: $42,9 \%$; comparativo: $44,6 \% ; p=0,89)$. Os grupos aniridia e comparativo apresentaram também proporções semelhantes de olhos com uma relação $E / D$ > a $0,8(23,8 \%$ vs. $30,4 \%, p=0,57)$. Nos olhos com glaucoma preexistente, uma progressão da relação $E / D \geq 0.2$ foi observada em $37,5 \%$ do grupo aniridia e $62,1 \%$ do grupo comparativo $(p=0,11)$.

Todos os olhos com aniridia sem glaucoma preexistente e sem implante de tubo profilático $(n=3,100,0 \%)$ desenvolveram um novo diagnóstico de glaucoma após a cirurgia de B-KPro tipo 1, definido como uma progressão de relação $E / D \geq 0,2$, em contraste, apenas sete de 25 olhos $(28,0 \%)$ no grupo comparativo desenvolveram $(p=0,01)$. Entretanto, notavelmente, nenhum dos olhos sem glaucoma preexistente e com implante de tubo profilático desenvolveu um novo diagnóstico de glaucoma. 
As análises de Kaplan-Meier mostraram probabilidades semelhantes ao longo do tempo para ambos os grupos em manter uma relação $E / D \leq 0,8$ ( $p=0,51$, Figura 4) ou progressão da relação $E / D$ menor que $0,2(p=0,92$, Figura 5).

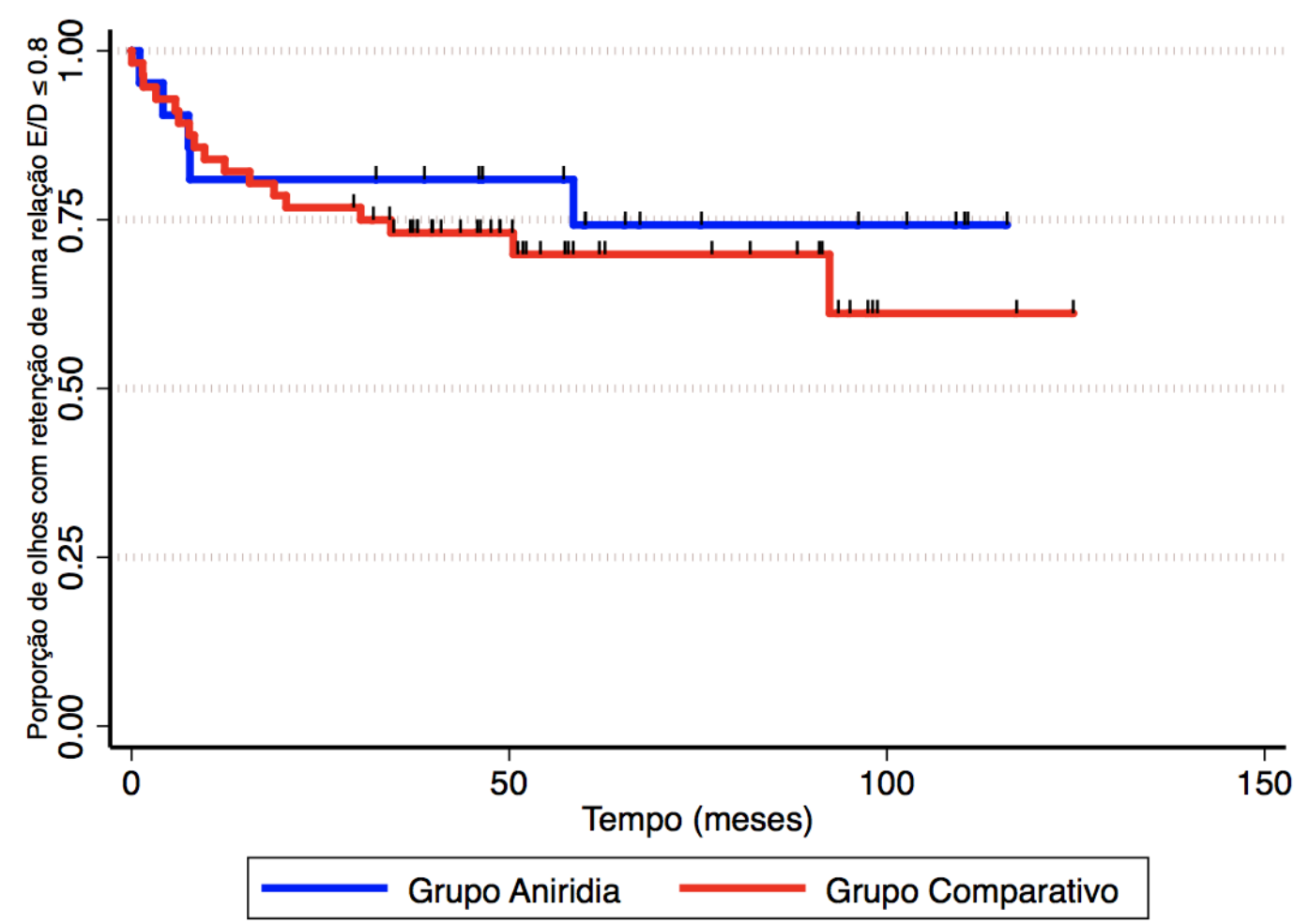

Figura 4 - Relação escavação/disco (E/D) menor ou igual a 0,8 após cirurgia de ceratoprótese tipo 1 de Boston nos grupos aniridia e comparativo. As curvas de Kaplan-Meier comparam a proporção de olhos nos grupos aniridia (linha azul) e comparativo (linha vermelha) ao longo do tempo que retiveram uma relação $E / D$ menor ou igual a 0,8. Ambos os grupos apresentaram similares proporções ao longo dos meses ( $p=0,51$, teste de log-rank) 


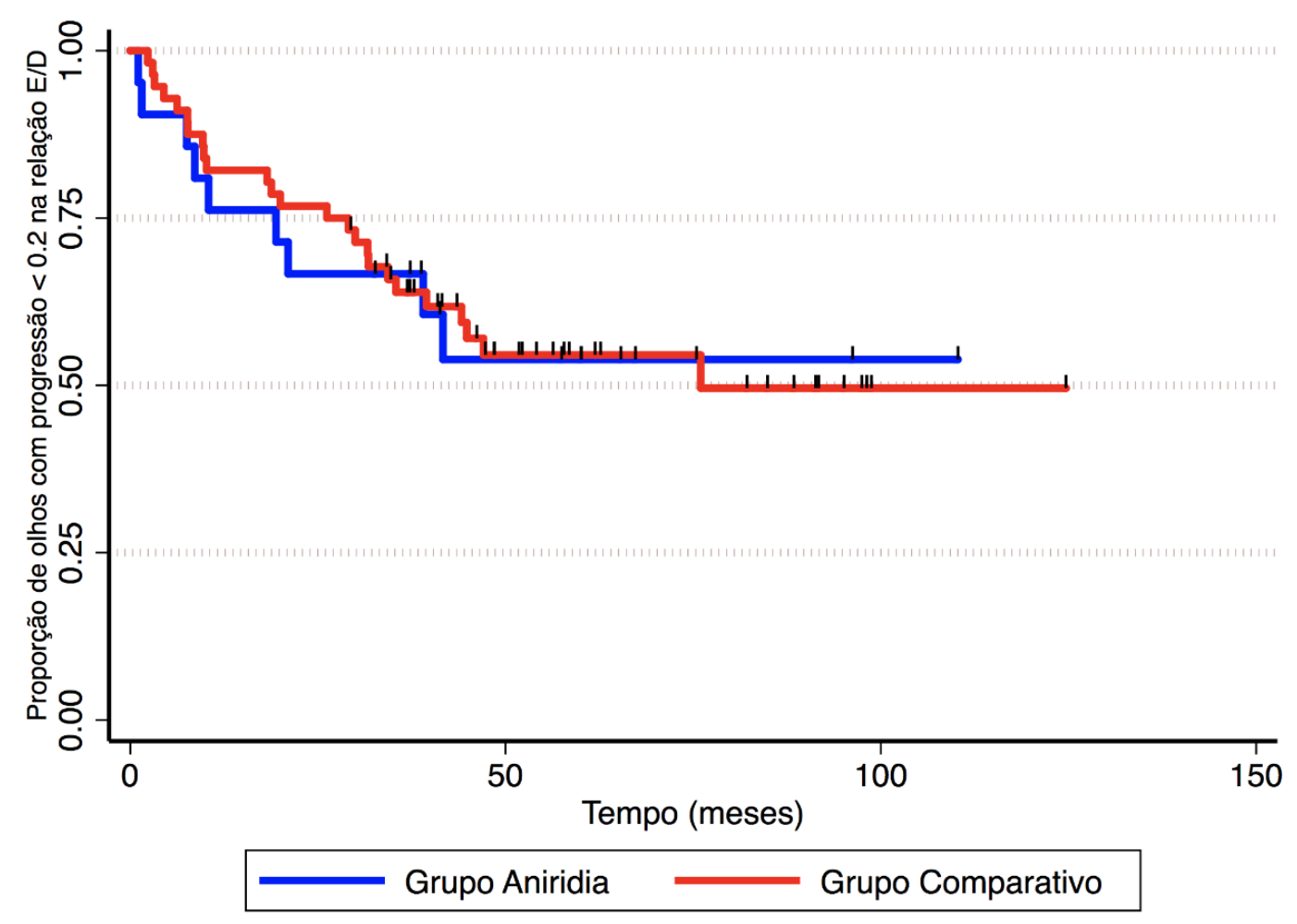

Figura 5 - Progressão da relação escavação/disco (E/D) menor que 0,2 após cirurgia de ceratoprótese tipo 1 de Boston nos grupos aniridia e comparativo. As curvas de Kaplan-Meier comparam a proporção de olhos nos grupos aniridia (linha azul) e comparativo (linha vermelha) ao longo do tempo que retiveram uma progressão na relação $E / D$ menor que 0,2. Ambos os grupos apresentaram similares proporções ao longo dos meses ( $p=0,92$, teste de log-rank) 


\subsection{Implante de drenagem para glaucoma e manejo das complicações relacionadas}

O grupo aniridia apresentou mais olhos com um tubo de drenagem para glaucoma implantado comparado ao segundo grupo $(77,3 \%$ vs. $44,3 \%$, respectivamente, $p=0,008$, Tabela 7 ). Um olho em cada grupo teve dois tubos implantados. Após a cirurgia de B-KPro tipo 1, porcentagens semelhantes de olhos com tubos nos grupos aniridia e comparativo desenvolveram, pelo menos, uma erosão do tubo $(55,6 \%$ vs. $35,7 \%$, $p=0,19)$. Entre os tubos implantados na câmara anterior no grupo aniridia, $35,7 \%$ tiveram um episódio de erosão e $28,6 \%$ mais de um episódio de erosão; esta proporção foi semelhante ao grupo comparativo $(38,9 \%$, $p=0,85$ e $11,1 \%, p=0,21$, respectivamente). Dos olhos com tubos implantados na pars plana (aniridia, quatro olhos; grupo comparativo, 11 olhos), um olho em cada grupo desenvolveu erosão do tubo. Todas as erosões dos tubos foram tratadas com abordagens cirúrgicas ou não cirúrgicas, por haver um risco significativo de endoftalmite associada à erosão do tubo nos olhos com B-KPro tipo $1^{51}$. Um tubo implantado na pars plana com vitrectomia concorrente em um paciente com aniridia requereu vitreólise com YAG laser para o tratamento de sua obstrução. 
Tabela 7 - Resultados dos implantes de drenagem para glaucoma

\begin{tabular}{|c|c|c|c|}
\hline & Grupo Aniridia & $\begin{array}{c}\text { Grupo } \\
\text { Comparativo }\end{array}$ & $\mathbf{p}$ \\
\hline Total de olhos, $\mathbf{n}$ & 22 & 61 & \\
\hline Com um tubo implantados & $17 / 22(77,3 \%)$ & $27 / 61(44,3 \%)$ & 0,008 \\
\hline Com dois tubos implantados & $1 / 22(4,5 \%)$ & $1 / 61(1,6 \%)$ & ND \\
\hline Olhos com tubo, $n$ & 18 & 28 * & \\
\hline Com, pelo menos, um episódio de erosão & $10 / 18(55,6 \%)$ & $10 / 28(35,7 \%)$ & 0,19 \\
\hline $\begin{array}{l}\text { Olhos com tubo implantado na câmara } \\
\text { anterior, } n\end{array}$ & 14 & 18 & \\
\hline Com uma erosão & $5 / 14(35,7 \%)$ & $7 / 18(38,9 \%)$ & 0,85 \\
\hline Com duas ou mais erosões & $4 / 14(28,6 \%)$ & $2 / 18(11,1 \%)$ & 0,21 \\
\hline $\begin{array}{l}\text { Olhos com tubo implantado na pars } \\
\text { plana, } n\end{array}$ & 4 & 11 & \\
\hline Com uma erosão & $1 / 4(25,0 \%)$ & $1 / 11(9,1 \%)$ & ND \\
\hline \multicolumn{4}{|l|}{ Tratamento } \\
\hline $\begin{array}{l}\text { Tratamento para erosões dos tubos } \\
\text { implantados na CA, } n \text { ** }\end{array}$ & 14 & 11 & \\
\hline Lente de contato com tamanho diferente & $3 / 14(21,4 \%)$ & $2 / 11(18,2 \%)$ & 0,84 \\
\hline $\begin{array}{l}\text { Patch de enxerto pericárdico ou de } \\
\text { córnea }\end{array}$ & $4 / 14(28,6 \%)$ & $5 / 11(45,5 \%)$ & 0,38 \\
\hline Tubo redirecionado para a pars plana & $3 / 14(21,4 \%)$ & $1 / 11(9,1 \%)$ & 0,40 \\
\hline Remoção do tubo apenas & $1 / 14(7,1 \%)$ & $2 / 11(18,2 \%)$ & 0,40 \\
\hline $\begin{array}{l}\text { Remoção do tubo e procedimento } \\
\text { ciclodestrutivo }\end{array}$ & $3 / 14(21,4 \%)$ & $1 / 11(9,1 \%)$ & 0,40 \\
\hline $\begin{array}{l}\text { Tratamento para erosões dos tubos } \\
\text { implantados na pars plana, } n\end{array}$ & 1 & 1 & \\
\hline Lente de contato com tamanho diferente & $1 / 1(100 \%)$ & $0 / 1(0 \%)$ & ND \\
\hline $\begin{array}{l}\text { Patch de enxerto pericárdico ou de } \\
\text { córnea }\end{array}$ & $0 / 1(0 \%)$ & $1 / 1(100 \%)$ & ND \\
\hline
\end{tabular}

NOTAS: * Um olho tem um tubo na câmara anterior e um outro tubo na pars plana.

** Alguns tubos tiveram mais de um episódio de erosão. O número de episódios total é relatado. 


\subsection{Outras complicações após a cirurgia de B-KPro tipo 1}

Após a cirurgia de B-KPro tipo 1, 45,5\% dos olhos de aniridia e $26,2 \%$ dos olhos do grupo comparativo desenvolveram um ou mais episódios de complicações com alto risco $(p=0.10)$. As mais comuns no grupo aniridia foram: descolamento de coroide ou hemorragia supracoroidiana relacionados à hipotonia (18,2\%), extrusão de B-KPro tipo 1 por necrose estromal não infecciosa (18,2\%); hemorragia vítrea (13,6\%); e descolamento de retina (13,6\%). No grupo comparativo, estas complicações ocorreram na proporção: descolamento de coroide ou hemorragia supracoroidiana relacionados à hipotonia $(1,6 \% \mathrm{p}=0,005)$; extrusão de $\mathrm{B}$ KPro tipo 1 por necrose estromal não infecciosa $(4,9 \%, p=0,06)$; hemorragia vítrea $(0 \%, p=0,003)$ e descolamento de retina $(4,9 \%, p=0,18)$. 
Tabela 8 - Prevalência cumulativa de complicações com risco de perda visual após a cirurgia de implante da ceratoprótese de Boston tipo 1

\begin{tabular}{|c|c|c|c|}
\hline Complicação com alto risco de perda visual & $\begin{array}{c}\text { Grupo } \\
\text { Aniridia } \\
\mathrm{n}=\mathbf{2 2} \text { olhos }\end{array}$ & $\begin{array}{c}\text { Grupo } \\
\text { Comparativo } \\
n=61 \text { olhos }\end{array}$ & $\mathbf{p}$ \\
\hline Olhos com, pelo menos, uma complicação & $10(45,5 \%)$ & $16(26,2 \%)$ & 0.10 \\
\hline Hemorragia vítrea & $3(13,6 \%)$ & $0(0 \%)$ & 0.003 \\
\hline $\begin{array}{l}\text { Descolamento de coroide ou hemorragia } \\
\text { supracoroidiana relacionada à hipotonia }\end{array}$ & $4(18,2 \%)$ & $1(1,6 \%)$ & 0.005 \\
\hline Vitreíte não infecciosa & $1(4,5 \%)$ & $6(9,8 \%)$ & 0.44 \\
\hline Endoftalmite & $1(4,5 \%)$ & $3(4,9 \%)$ & 0.94 \\
\hline Descolamento de retina & $3(13,6 \%)$ & $3(4,9 \%)$ & 0.18 \\
\hline Ceratite infecciosa sem endoftalmite & $1(4,5 \%)$ & $1(1,6 \%)$ & ND \\
\hline Extrusão por necrose estromal não infecciosa & $4(18,2 \%)$ & $3(4,9 \%)$ & 0.06 \\
\hline $\begin{array}{l}\text { Substituição por ceratite infecciosa ou } \\
\text { endoftalmite }\end{array}$ & $0(0 \%)$ & $4(6,6 \%)$ & 0.22 \\
\hline
\end{tabular}

NOTAS: Alguns olhos apresentaram mais de um tipo de complicação. Se o mesmo olho teve a mesma complicação mais de uma vez, foi registrado apenas um episódio.

O valor de p não estará disponível se o número de olhos em ambos os grupos for menor que 2.

ND = não disponível. 
Embora mais olhos com aniridia tenham desenvolvido descolamento

de coroide ou hemorragia supracoroidiana relacionada à hipotonia quando comparados aos olhos no grupo comparativo ( $p=0.005$, Tabela 8$)$, nenhum dos olhos com implante de tubo profilático desenvolveu esse tipo de complicação. Os dados da Tabela 9 descrevem com detalhes os casos que tiveram essa complicação.

Tabela 9 - Descrição dos casos de descolamento de coroide ou hemorragia supracoroidiana relacionados à hipotonia

\begin{tabular}{|c|c|c|c|}
\hline $\begin{array}{c}\text { Grupo/ } \\
\text { indicação da B- } \\
\text { KPro tipo } 1\end{array}$ & $\begin{array}{l}\text { AV } \\
\text { prévia ao } \\
\text { implante }\end{array}$ & AV final & Descrição \\
\hline $\begin{array}{l}\text { Comparativo/ } \\
\text { Úlcera de Mooren }\end{array}$ & MM & SPL & $\begin{array}{l}\text { Descolamento de retina e efusão de coróide, } \\
\text { após substituição da B-KPro tipo } 1 \text { por ceratitie } \\
\text { infecciosa e endoftalmite. Caso tratado com } \\
\text { vitrectomia com resolução da hipotonia e } \\
\text { pressão intraocular de } 25 \mathrm{mmHg} \text { no último } \\
\text { seguimento. }\end{array}$ \\
\hline $\begin{array}{l}\text { Aniridia/ } \\
\text { Ceratopatia } \\
\text { associada à } \\
\text { aniridia }\end{array}$ & $20 / 200$ & $20 / 200$ & $\begin{array}{l}\text { Hemorragia supracoroidiana no primeiro dia } \\
\text { após implante do tubo de drenagem para } \\
\text { tratamento do glaucoma ( } 13 \text { meses após } \\
\text { implante da B-KPro tipo 1). Resolução do caso, } \\
\text { com pressão intraocular no último seguimento } \\
\text { de } 16 \mathrm{mmHg} \text {. }\end{array}$ \\
\hline $\begin{array}{l}\text { Aniridia/ } \\
\text { Ceratopatia } \\
\text { associada à } \\
\text { aniridia }\end{array}$ & MM & $20 / 1250$ & $\begin{array}{l}\text { Efusão de coroide no terceiro dia após implante } \\
\text { de tubo de drenagem para tratamento do } \\
\text { glaucoma ( } 14 \text { meses após implante da B-KPro } \\
\text { tipo 1). Resolução do caso, com pressão } \\
\text { intraocular no último seguimento de } 12 \mathrm{mmHg} \text {. }\end{array}$ \\
\hline $\begin{array}{l}\text { Aniridia/ } \\
\text { Ceratopatia } \\
\text { associada à } \\
\text { aniridia }\end{array}$ & CD & CD & $\begin{array}{l}\text { Efusão de coroide espontânea } 8 \text { meses após } \\
\text { implante de tubo de drenagem para tratamento } \\
\text { do glaucoma (concomitante ao implante de B- } \\
\text { KPro). Resolução do caso, com pressão } \\
\text { intraocular no último seguimento de } 17 \mathrm{mmHg} \text {. }\end{array}$ \\
\hline $\begin{array}{l}\text { Aniridia/ } \\
\text { Ceratopatia } \\
\text { associada à } \\
\text { aniridia }\end{array}$ & CD & PL & $\begin{array}{l}\text { Exposição do prato e do tubo de drenagem } \\
\text { tratados com remoção de ambos e } \\
\text { ciclofotocoagulação. Efusão de coroide } 7 \text { dias } \\
\text { após o procedimento cirúrgico. Hipotonia } \\
\text { mantida com pressão intraocular de } 2 \mathrm{mmHg} \text { no } \\
\text { último seguimento. }\end{array}$ \\
\hline
\end{tabular}

NOTAS: $B-K P r o=$ ceratoprótese de Boston; $A V=$ acuidade visual corrigida; $C D=$ contagem de dedos; $\mathrm{MM}=$ movimento de mãos; $\mathrm{PL}=$ percepção de luz; $\mathrm{SPL}=$ sem percepção de luz. 


\subsection{Tratamento com equipe composta por especialistas em córnea, glaucoma e retina}

Antes da cirurgia B-KPro tipo 1, uma porcentagem significativamente maior de pacientes com aniridia foi avaliada por um especialista em glaucoma $(68,2 \%)$ em comparação com o segundo grupo $(39,3 \%, p=0,02$, Tabela 10), enquanto porcentagens semelhantes foram avaliadas por um especialista em retina $(22,7 \%$ vs. $32,8 \%, p=0,38)$. Após o implante de $B$ KPro tipo $1,90,9 \%$ do grupo aniridia e $70,5 \%$ do grupo comparativo receberam cuidados de um especialista em glaucoma $(p=0,06)$ enquanto $77,3 \%$ do grupo aniridia e $50,8 \%$ do grupo comparativo receberam cuidados de um especialista em retina $(p=0,03)$. Todos os pacientes do estudo foram acompanhados por um especialista em córnea durante o período de acompanhamento.

Tabela 10 - Avaliação pelos especialistas em glaucoma e retina

\begin{tabular}{lccc}
\hline & $\begin{array}{c}\text { Grupo } \\
\text { Aniridia } \\
\mathbf{n = 2 2} \text { olhos }\end{array}$ & $\begin{array}{c}\text { Grupo } \\
\text { Comparativo } \\
\mathbf{n = 6 1} \text { olhos }\end{array}$ & $\mathbf{p}$ \\
\hline Especialista em glaucoma antes do implante & $15(68,2 \%)$ & $24(39,3 \%)$ & $\mathbf{0 , 0 2}$ \\
Especialista em retina antes do implante & $5(22,7 \%)$ & $20(32,8 \%)$ & 0,38 \\
Especialista em glaucoma após o implante & $20(90,9 \%)$ & $43(70,5 \%)$ & 0,06 \\
Especialista em retina após o implante & $17(77,3 \%)$ & $31(50,8 \%)$ & $\mathbf{0 , 0 3}$ \\
\hline
\end{tabular}


6 Discussão 


\section{DISCUSSÃO}

O presente estudo demonstrou que apesar de os pacientes com aniridia terem maior prevalência de glaucoma prévia ao implante da B-KPro tipo 1, eles apresentaram proporções similares de acuidade visual e de progressão do glaucoma no pós-operatório, comparados aos pacientes com outras indicações em um tempo médio de seguimento superior a 5 anos. 0 tubo de drenagem para glaucoma implantado profilaticamente durante a cirurgia de B-KPro tipo 1 reduziu drasticamente a taxa de glaucoma no pósoperatório no grupo aniridia, destacando, assim, a importância do controle da pressão intraocular de forma agressiva.

Este estudo demonstrou a prevalência de glaucoma em olhos com aniridia em $76,2 \%$ antes do implante da B-KPro, que é similar às taxas relatadas em outros estudos ${ }^{18,19}$. Neste estudo, preferiu-se adotar como critério para progressão ou para o diagnóstico de glaucoma, o aumento, igual ou superior, na relação E/D de 0,2. Entretanto, outros trabalhos com avaliação de pacientes com aniridia submetidos à B-KPro tipo 1 definiram progressão ou diagnóstico de glaucoma como terapia adicional medicamentosa, cirúrgica, ou não descreveram seus critérios ${ }^{18,19}$. Assim, não foi possível a comparação dos resultados relacionados à progressão ou ao diagnóstico. Portanto, os resultados foram avaliados com um grupo comparativo, no qual os olhos foram submetidos à cirurgia de B-KPro tipo 1 com AV pré-operatória e tempo de seguimento semelhantes. Após a cirurgia, 
não houve diferenças significativas entre os grupos nessa variável. No entanto, diferentemente do grupo comparativo, todos os olhos com aniridia sem diagnóstico prévio e sem implante profilático de drenagem desenvolveram o glaucoma no pós-operatório.

Os resultados semelhantes entre os dois grupos relacionados à progressão ou surgimento do glaucoma podem ser explicados por algumas hipóteses. O implante da B-KPro tipo 1 aumenta esse risco, em razão de inflamação crônica relacionada ao trauma cirúrgico e ao fechamento angular progressivo associado a mudanças biomecânicas na câmara anterior induzida pela prótese $55,57,58,78$. Neste estudo, os dados perioperatórios foram comparáveis nos dois grupos. Portanto, mudanças biomecânicas na câmara anterior podem ser consideradas similares. Segundo, embora houvesse mais glaucoma preexistente no grupo aniridia, este mesmo foi submetido a maiores números de avaliações pré-operatórias por um especialista em glaucoma e de cirurgias para tratamento dessa afecção durante e após a cirurgia de B-KPro tipo 1. O tratamento, considerado mais agressivo do glaucoma no grupo aniridia pode ter repercutido em relativos melhores resultados. Terceiro, o grupo comparativo apresentou taxas mais altas de ceratoplastia prévia, o que poderia aumentar o risco ou gravidade de glaucoma ${ }^{79}$. Adicionalmente, os pacientes com aniridia eram mais jovens do que os do grupo comparativo. A prevalência de glaucoma aumenta com a idade ${ }^{80}$, embora o efeito da idade no glaucoma relacionado ao B-KPro tipo 1 não tenha sido totalmente investigado ${ }^{81}$. 
O monitoramento e o manejo cuidadoso do glaucoma são aspectos importantes no cuidado dos pacientes com B-KPro tipo 1, sobretudo em pacientes com aniridia 19,55. Com base nos resultados deste estudo, recomenda-se que um implante de drenagem de glaucoma seja realizado previamente ou concomitantemente à cirurgia de B-KPro tipo 1 em pacientes com aniridia sem nenhum implante funcional, com ou sem glaucoma preexistente. Os resultados mostraram que a cirurgia profilática do implante de drenagem preveniu o surgimento de glaucoma em todos os olhos com aniridia após a cirurgia de B-KPro tipo 1. No entanto, houve altas taxas de erosões em tubos colocados na câmara anterior (total de 64,3\% com, pelo menos, uma erosão no grupo aniridia), presumivelmente, em razão da fricção mecânica da lente de contato aumentada pelo nistagmo ${ }^{51,52}$. As erosões devem ser tratadas de forma agressiva pelo alto risco de endoftalmite em pacientes com B-KPro tipo $1^{51}$. O implante do tubo pela pars plana pode diminuir o risco de erosão do tubo, embora a oclusão possa ocorrer em razão de uma vitrectomia incompleta.

Com o controle agressivo do glaucoma, o estudo mostrou que a BKPro tipo 1 possa ser uma opção viável para a reabilitação visual a longo prazo em pacientes com aniridia. Como resultado, $72,7 \%$ dos olhos com aniridia apresentaram melhora da acuidade visual após a cirurgia. Nenhum dos olhos com aniridia desenvolveu acuidade visual de não percepção luminosa, enquanto $13,6 \%$ dos olhos apresentaram a acuidade visual de percepção luminosa no final do seguimento, dois casos relacionados ao descolamento de retina e um caso à hipotonia e à efusão de coroide. Este 
resultado contrapõe-se ao estudo de Muzychuk et al., que relataram a visão de SPL em oito de 23 (34,8\%) olhos com aniridia após o implante de B-KPro tipo 1, com cinco casos em razão do descolamento de retina inoperável, dois pelo glaucoma terminal, e um pela extrusão da prótese ${ }^{25}$.

Os desfechos após o implante da B-KPro tipo 1 são complexos e dependem de inúmeras variáveis, incluindo diagnósticos prévios à cirurgia, doença retiniana e glaucomatosa pré-operatória, complicações pósoperatórias, como a progressão do glaucoma ${ }^{82}$. A exemplo, o aumento da expressão de citocinas inflamatórias nos olhos com B-KPro tipo 1 pode desempenhar um papel importante na apoptose das células ganglionares retinianas $78,83,84$. É importante ressaltar em nosso estudo que o grupo aniridia apresentou maior proporção de complicações com risco de perda visual $(45,5 \%)$ e a falta de diferença significantemente estatística do segundo grupo poderia ser em razão do pequeno tamanho da amostra. Assim, é indicado o acompanhamento não só com o especialista em córnea, mas também com especialistas em glaucoma e retina, quando necessário. 0 manejo agressivo é de extrema importância para a preservação de um bom resultado visual em pacientes com aniridia após o implante da B-KPro tipo 1.

\subsection{Limitações}

O estudo tem as limitações inerentes de um estudo retrospectivo, com a possibilidade de uma coleta de dados não uniforme, embora a minimização desse viés tenha sido realizada ao se determinar critérios 
específicos de inclusão e exclusão. A heterogeneidade nas doenças subjacentes do grupo comparativo pode ter resultado em múltiplas variáveis de confusão. A análise da formação de membrana retroprotética não foi realizada pela dificuldade para analisar as características de cada membrana em um estudo retrospectivo. Diferentes características destas, como espessamento e vascularização, podem contribuir para a necrose estromal e para a falha da B-KPro tipo $1{ }^{85,86}$. Pelo fato da aniridia ser uma condição relativamente rara, o estudo incluiu uma amostra pequena, o que pode ter gerado um baixo poder estatístico e, portanto, a incapacidade de detectar diferenças entre os grupos. Finalmente, medidas do dano glaucomatoso com campo visual e com imagens de nervo óptico não foram incluídas na análise, em razão da qualidade afetada pelo nistagmo, altamente prevalente no grupo aniridia. Assim, a relação escavação/disco foi baseada na avaliação subjetiva. 
7 Conclusões 


\section{CONCLUSÕES}

- Embora a alta incidência de glaucoma e outras complicações possam proporcionar risco de perda visual, a cirurgia de BKPro tipo 1 pode levar à reabilitação visual a longo prazo em pacientes com aniridia, quando o controle da pressão intraocular e das complicações for realizado de forma agressiva por uma equipe de especialistas treinados.

- Antes da cirurgia da B-KPro tipo 1, recomenda-se que todos os pacientes sejam avaliados por um especialista em glaucoma. $\mathrm{O}$ implante prévio ou concomitante de tubo de drenagem profilático é altamente recomendado a todos os pacientes com aniridia submetidos ao implante de B-KPro tipo 1.

- No pós-operatório, é necessária uma estreita coordenação dos cuidados entre especialistas em córnea e em glaucoma para prevenir a progressão do glaucoma. Esta abordagem pode proporcionar uma melhora nos resultados visuais da cirurgia de B-KPro tipo 1 e limitar a perda de visão secundária ao dano glaucomatoso em pacientes com aniridia. 
8 Anexos 


\section{Anexo 1 - Aprovação do Comitê de Estudos Humanos do Conselho de Revisão Institucional (Institutional Review Board- IRB) do hospital Massachusetts Eye and Ear.}

Massachusetts Eye and Ear
Human Studies Committee HSCQmeeinarrardedu

\section{PROTOCOL APPROVAL}

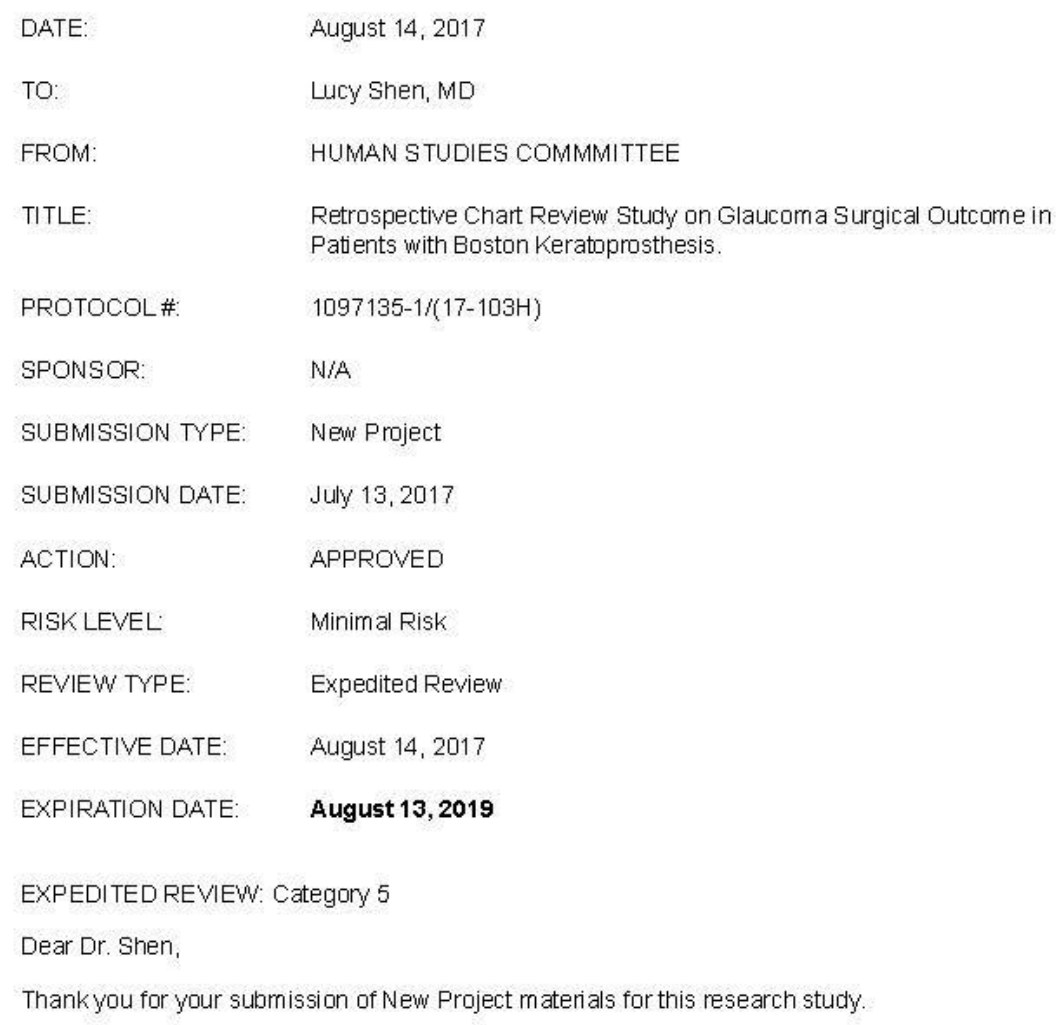

This protocol has been reviewed and approved by the HSC. During the review of this protocol, the HSC specifically considered (i) the minimization of risks to subjects (ii) the risks and anticipated benefits, if ary, to subjects; (iii) the equitable selection of subjects; (iv) the procedures for obtaining and documenting informed consent, (v) the monitoring of data related to subject safety, and (vi) subject privacy and confidentiality of data in accordance with 45 CFR 46.111 and 21 CFR 56.111, criteria for IRB approval of research.

\section{Notes, Determinations, Findings:}

Waiver of Consent/Authorization: A waiver of Consent/Authorization has been approved in accordance with the Common Rule and Privacy Rule regulations for the entire study. 


\section{Anexo 2 - Aprovação do Comitê de Ética em Pesquisa da Faculdade de Medicina da Universidade de São Paulo.}

USP - FACULDADE DE
MEDICINA DA UNIVERSIDADE
DE SÃO PAULO - FMUSP
PAREcoformo
PARECE CONSUBSTANCIADO DO CEP

\section{DADOS DO PROJETO DE PESQUISA}

Título da Pesquisa: CERATOPRÓtese de BOSTON TIPO 1 EM PACIENTES COM ANIRIDIA Pesquisador: MILTON RUIZ ALVES

Área Temática:

Versão: 1

CAAE: 80486017.6 .0000 .0065

Instituição Proponente: Departamento de Oftalmologia e Otorrinolaringologia

Patrocinador Principal: Financiamento Próprio

DADOS DO PARECER

Número do Parecer: 2.435.117

Apresentação do Projeto:

Trata-se de um estudo descritivo observacional longitudinal retrospectivo com finalidade acadêmica de doutorado na qual a coleta de dados será realizada no hospital Massachusetts Eye and Ear (Boston, EUA) em colaboração com a pesquisadora Dra. Lucy Shen do mesmo hospital. O projeto lidará com avaliação de pacientes portadores de ceratopatia secundária a aniridia congênita submetidos a cerato prótese de Boston tipo 1, em instituição onde o procedimento doi criada (Mass Eye and Ear). Os dados dos pacientes serão coletados de prontuários e exames a partir de banco de dados de estudos anteriores da Dra. Shen complementado com exames oftalmológicos, tais como papilografia, campimetria visual e outros. $\mathrm{O}$ projeto em questão já foi aprovado pelo comitê de ética local (IRB - Institutional Review Board), cuja cópia esta anexada ao processo, identificado como "Retrospective chart review study on glaucoma surgical outcome in patients with Boston keratoprosthesis", em cujo parecer, no. 1097135-1/(17-103H), há recomendações explícitas para preservação da privacidade dos sujeitos (pacientes) e confidencialidade dos dados de acordo com as normas americanas 45 CFR.111 e 21 CFR 56.111 para sua aprovação, que parece estar sendo contemplado na descrição do projeto. Há também aprovação para autorização para dispensa do TCLE. Há data de expiração IRB americano estabelecido para o dia 13/08/2019, assim se houver necessidade de prorrogação projeto, há necessidade de solicitação de nova aprovação com 6 a 8 semanas de antecedência ao HSC (HUMAN STUDIES COMMMITTEE ) do Massachusetts Eye and Ear da Harvard University.

Endereço: DOUTOR ARNALDO $25121^{\circ}$ andar sala 36

Bairro: PACAEMBU CEP: 01.246-903

UF: SP Município: SAO PAULO

Telefone: (11)3893-4401 E-mail: cep.fm@usp.br 


\section{USP - FACULDADE DE MEDICINA DA UNIVERSIDADE DE SÃO PAULO - FMUSP}

Continuação do Parecer. 2.435.117

\section{Objetivo da Pesquisa:}

Avaliar o resultado do implante da ceratoprótese tipo 1 de Boston em pacientes com ceratopatia secundária a aniridia congênita da casuística do hospital Massachusetts Eye and Ear (Harvard University). Estudar o desenvolvimento, progressão e manejo do glaucoma que possam gerar bases para futuras diretrizes médicas e cirúrgicas e consequentemente nortear o tratamento e manuseio dos pacientes com aniridia congênita submetidos a cirurgia de ceratoprótese tipo 1 de Boston de oftalmologistas brasileiros.

\section{Avaliação dos Riscos e Benefícios:}

Risco mínimo na manutenção da privacidade e confidencialidade em que nas etapas iniciais será necessário acessar dados de identidade dos pacientes para consolidação do banco de dados. Os benefícios decorrentes deste estudo é indireto na medida que os conhecimentos obtidos deste estudo poderão beneficiar futuros pacientes.

\section{Comentários e Considerações sobre a Pesquisa:}

Esta será a maior casuística de casos de implante de ceratoprótese de Boston tipo 1 em pacientes portadores de ceratopatia secundária a aniridia congênita obtida na instituição inventora do implante. Segundo o projeto apresentado o implante tem sido continuamente aperfeiçoado desde a sua invenção em 1968 e aprovação pela FDA em 1992 para minimização dos efeitos indesejáveis do implante.

Apesar de as motivantes e justificativas estejam claras e sejam relevantes, o planejamento dos métodos de análise dos dados é insuficiente e precisaria ser melhor e mais detalhadamente delineada para constituir um projeto no nível de doutorado. Isso é tão mais relevante na medida que este é um trabalho essencialmente de análise estatística de dados.

\section{Considerações sobre os Termos de apresentação obrigatória:}

A apresentação do TCLE foi dispensada pelo parecer do comitê ética (IRB) do hospital Massachusetts Eye and Ear, cuja cópia e sua traduçãoo estão anexadas ao processo submetido a este Comitê.

\section{Recomendações:}

Este comitê não vê óbices éticos no projeto, porém como boa prática científica para condução do projeto de tese de doutorado recomenda-se um delineamento prévio dos procedimentos de análise de dados que serão utilizados bem como delinear as hipóteses científicas que se pretende

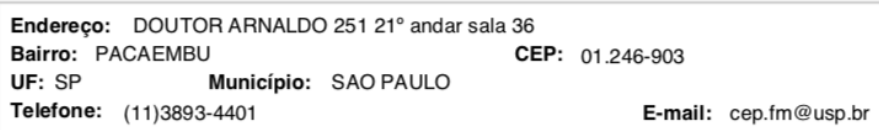




\section{USP - FACULDADE DE MEDICINA DA UNIVERSIDADE DE SÃO PAULO - FMUSP}

Continuação do Parecer. 2.435.117

responder com o trabalho que será desenvolvido.

Conclusões ou Pendências e Lista de Inadequações:

Não há óbices ou pendências éticas para realização do projeto. Observa-se no entanto deficiência importante no delineamento da metodologia que será usada para análise dos dados coletados.

Considerações Finais a critério do CEP:

Este parecer foi elaborado baseado nos documentos abaixo relacionados:

\begin{tabular}{|c|c|c|c|c|}
\hline Tipo Documento & Arquivo & Postagem & Autor & Situação \\
\hline $\begin{array}{l}\text { Informações Básicas } \\
\text { do Projeto }\end{array}$ & $\begin{array}{l}\text { PB_INFORMAÇŌES_BÁSICAS_DO_P } \\
\text { ROJETO 1029891.pdf }\end{array}$ & $\begin{array}{c}28 / 11 / 2017 \\
17: 04: 20 \\
\end{array}$ & & Aceito \\
\hline Folha de Rosto & FR_Projeto_Tese.pdf & $\begin{array}{c}28 / 11 / 2017 \\
17: 03: 10\end{array}$ & $\begin{array}{l}\text { MILTON RUIZ } \\
\text { ALVES }\end{array}$ & Aceito \\
\hline Outros & $\begin{array}{l}\text { CEP_FMUSP_Cadastro_Tese_Rafaella. } \\
\text { pdf }\end{array}$ & $\begin{array}{c}28 / 11 / 2017 \\
17: 02: 42\end{array}$ & $\begin{array}{l}\text { MILTON RUIZ } \\
\text { ALVES }\end{array}$ & Aceito \\
\hline Outros & $\begin{array}{l}\text { OFICIO_365_APROVACAO_DEPTO_O } \\
\text { FTALMOLOGIA.pdf }\end{array}$ & $\begin{array}{c}28 / 11 / 2017 \\
17: 01: 27\end{array}$ & $\begin{array}{l}\text { MILTON RUIZ } \\
\text { ALVES }\end{array}$ & Aceito \\
\hline Outros & $\begin{array}{l}\text { Carta_de_Concordancia_da_contribuica } \\
\text { o_da_Dra_Lucy_Shen_em_ingles.pdf }\end{array}$ & $\begin{array}{c}09 / 11 / 2017 \\
08: 17: 44\end{array}$ & $\begin{array}{l}\text { MILTON RUIZ } \\
\text { ALVES }\end{array}$ & Aceito \\
\hline Outros & $\begin{array}{l}\text { Aprovacao_do_Protocolo_do_Comite_d } \\
\text { e Etica Mass_Eye and Ear.pdf }\end{array}$ & $\begin{array}{c}09 / 11 / 2017 \\
08: 17: 21\end{array}$ & $\begin{array}{l}\text { MILTON RUIZ } \\
\text { ALVES }\end{array}$ & Aceito \\
\hline Outros & $\begin{array}{l}\text { Traducao_Carta_Concordancia_da_Dra } \\
\text { Lucy Shen.pdf }\end{array}$ & $\begin{array}{c}09 / 11 / 2017 \\
08: 17: 00\end{array}$ & $\begin{array}{l}\text { MILTON RUIZ } \\
\text { ALVES }\end{array}$ & Aceito \\
\hline Outros & $\begin{array}{l}\text { Traducao_da_Aprovacao_Comite_de_Et } \\
\text { ica Mass Eve and Ear.pdf }\end{array}$ & $\begin{array}{c}09 / 11 / 2017 \\
08: 16: 41\end{array}$ & $\begin{array}{l}\text { MILTON RUIZ } \\
\text { ALVES }\end{array}$ & Aceito \\
\hline $\begin{array}{l}\text { Projeto Detalhado / } \\
\text { Brochura } \\
\text { Investigador }\end{array}$ & Projeto_K_pro_aniridia.doc & $\begin{array}{c}09 / 11 / 2017 \\
08: 12: 23\end{array}$ & $\begin{array}{l}\text { MILTON RUIZ } \\
\text { ALVES }\end{array}$ & Aceito \\
\hline
\end{tabular}

Situação do Parecer:

Aprovado

Necessita Apreciação da CONEP:

Não

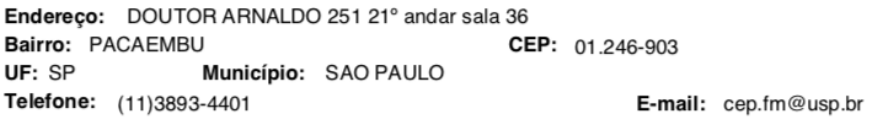




USP - FACULDADE DE
MEDICINA DA UNIVERSIDADE Platoforma
DE SÃO PAULO - FMUSP

SAO PAULO, 13 de Dezembro de 2017

Assinado por:

Maria Aparecida Azevedo Koike Folgueira

(Coordenador)

Endereço: DOUTOR ARNALDO $25121^{\circ}$ andar sala 36

Bairro: PACAEMBU CEP: $01.246-903$

UF: SP Município: SAO PAULO

Telefone: (11)3893-4401

E-mail: cep.fm@usp.br 
9 Referências 


\section{REFERÊNCIAS}

1. van Heyningen V, Williamson KA. PAX6 in sensory development. Hum Mol Genet. 2002;11(10):1161-7.

2. Hingorani M, Williamson KA, Moore AT, van Heyningen V. Detailed ophthalmologic evaluation of 43 individuals with PAX6 mutations. Invest Ophthalmol Vis Sci. 2009;50(6):2581-90.

3. Nelson LB, Spaeth GL, Nowinski TS, Margo CE, Jackson L. Aniridia. A review. Surv Ophthalmol. 1984;28(6):621-42.

4. Edén U, Iggman D, Riise R, Tornqvist K. Epidemiology of aniridia in Sweden and Norway. Acta Ophthalmol. 2008;86(7):727-9.

5. Lee $H$, Khan $R$, O'keefe $M$. Aniridia: current pathology and management. Acta Ophthalmol. 2008;86(7):708-15.

6. Lee HJ, Colby KA. A review of the clinical and genetic aspects of aniridia. Semin Ophthalmol. 2013;28(5-6):306-12.

7. Chen TC, Walton DS. Goniosurgery for prevention of aniridic Glaucoma. Arch Ophthalmol. 1999;117:1144-8.

8. Grant WM, Walton DS. Progressive changes in the angle in congenital aniridia, with development of glaucoma. Trans Am Ophthalmol Soc. 1974;72:207-28.

9. Nishida K, Kinoshita S, Ohashi Y, Kuwayama Y, Yamamoto S. Ocular surface abnormalities in aniridia. Am J Ophthalmol. 1995;120(3):36875. 
10. De La Paz MF, Alvarez De Toledo J, Barraquer RI, Barraquer J. Longterm visual prognosis of corneal and ocular surface surgery in patients with congenital aniridia. Acta Ophthalmol. 2008;86(7):735-40.

11. Edén U, Riise R, Tornqvist K. Corneal involvement in congenital aniridia. Cornea. 2010;29(10):1096-102.

12. Gomes JA, Eagle RC, Gomes AK, Rapuano CJ, Cohen EJ, Laibson PR. Recurrent keratopathy after penetrating keratoplasty for aniridia. Cornea. 1996;15(5):457-62.

13. Kremer I, Rajpal RK, Rapuano CJ, Cohen EJ, Laibson PR. Results of penetrating keratoplasty in aniridia. Am J Ophthalmol. 1993;115(3): 317-20.

14. Ang AY, Chan CC, Biber JM, Holland EJ. Ocular surface stem cell transplantation rejection: Incidence, characteristics, and outcomes. Cornea. 2013;32(3):229-36.

15. Eslani M, Haq Z, Movahedan A, Moss A, Baradaran-Rafii A, Mogilishetty G, Holland EJ, Djalilian AR. Late acute rejection after allograft limbal stem cell transplantation: evidence for long-term donor survival. Cornea. 2017;36(1):26-31.

16. Akpek EK, Harissi-Dagher M, Petrarca R, Butrus SI, Pineda R 2nd, Aquavella JV, Dohlman $\mathrm{CH}$. Outcomes of Boston keratoprosthesis in aniridia: a retrospective multicenter study. $A m J$ Ophthalmol. 2007;144(2):227-31.

17. Rixen JJ, Cohen AW, Kitzmann AS, Wagoner MD, Goins KM. Treatment of aniridia with Boston type I keratoprosthesis. Cornea. 2013;32(7):947-50. 
18. Hassanaly SI, Talajic JC, Harissi-Dagher M. Outcomes following Boston type 1 keratoprosthesis implantation in aniridia patients at the University of Montreal. Am J Ophthalmol. 2014;158(2):270-6.

19. Shah KJ, Cheung AY, Holland EJ. Intermediate-term and long-term outcomes with the Boston type 1 keratoprosthesis in aniridia. Cornea. 2018;37(1):11-4.

20. Netland PA, Terada $\mathrm{H}$, Dohlman $\mathrm{CH}$. Glaucoma associated with keratoprosthesis. Ophthalmology. 1998;105(4):751-7.

21. Aldave AJ, Kamal KM, Vo RC, Yu F. The Boston type I keratoprosthesis: improving outcomes and expanding indications. Ophthalmology. 2009;116(4):640-51.

22. Greiner MA, Li JY, Mannis MJ. Longer-term vision outcomes and complications with the Boston type 1 keratoprosthesis at the University of California, Davis. Ophthalmology. 2011;118(8):1543-50.

23. Talajic JC, Agoumi Y, Gagné S, Moussally K, Harissi-Dagher M. Prevalence, progression, and impact of glaucoma on vision after boston type 1 keratoprosthesis surgery. Am J Ophthalmol. 2012; 153(2):267-74.

24. Banitt M. Evaluation and management of glaucoma after keratoprosthesis. Curr Opin Ophthalmol. 2011;22(2):133-6.

25. Muzychuk AK, Durr GM, Shine JJ, Robert MC, Harissi-Dagher M. No light perception outcomes following Boston keratoprosthesis type 1 Surgery. Am J Ophthalmol. 2017;181:46-54.

26. Doane MG, Dohlman $\mathrm{CH}$, Bearse G. Fabrication of a keratoprosthesis. Cornea. 1996;15(2):179-84. 
27. Saeed HN, Shanbhag S, Chodosh J. The Boston keratoprosthesis. Curr Opin Ophthalmol. 2017;28(4):390-6.

28. Shanbhag SS, Saeed HN, Colby KA, Chodosh J. Comparative outcomes of Boston keratoprosthesis type 1 implantation based on vision in the contralateral eye. Cornea. 2018;37(11):1408-13.

29. Dohlman $\mathrm{CH}$, Harissi-Dagher M, Graney J. The Boston keratoprosthesis: a new threadless design. Digital Journal of Ophthalmolmology [serial online]. 2007;13(3). Available at: http://www.djo.harvard.edu/site.php?url=/physicians/oa/1055

Published September 5, 2007. Accessed June 15, 2015.

30. Salvador-Culla B, Kolovou PE. Keratoprosthesis: a review of recent advances in the field. J Funct Biomater. 2016;7(2):13.

31. Taniguchi EV, Paschalis EI, Crnej A, Ren A, Colby KA, Chodosh J, Pasquale LR, Shen LQ, Dohlman CH, Cruzat A. The role of the back plate in angle anatomy with the Boston type I keratoprosthesis. Cornea. 2017;36(9):1096-101.

32. Todani A, Ciolino JB, Ament JD, Colby KA, Pineda R, Belin MW, Aquavella JV, Chodosh J, Dohlman $\mathrm{CH}$. Titanium back plate for a PMMA keratoprosthesis: clinical outcomes. Graefe's Arch Clin Exp Ophthalmol. 2011;249(10):1515-18.

33. Utine CA, Tzu J, Dunlap K, Akpek EK. Visual and clinical outcomes of explantation versus preservation of the intraocular lens during keratoprosthesis implantation. J Cataract Refract Surg. 2011;37(9): 1615-22. 
34. Dohlman $\mathrm{CH}$, Abad JC, Dudenhoefer EJ, Graney JM. Keratoprosthesis: beyond corneal graft failure. In: Spaeth GL E, ed. Ophthalmic surgery: principles and practice. 3rd ed. Philadelphia: W.B. Saunders; 2002. p.199-207.

35. Schneider LR, Hannush SB. Boston keratoprosthesis type I: surgical techniques. In: Cortina MS, de la Cruz J, eds. Keratoprostheses and Artificial Corneas: Fundamentals and surgical applications. Berlin, Heidelberg: Springer Berlin Heidelberg; 2015. p.77-80.

36. Vajaranant TS, Blair MP, McMahon T, Wilensky JT, De La Cruz J. Special considerations for pars plana tube-shunt placement in Boston type 1 keratoprosthesis. Arch Ophthalmol. 2010;128(11):1480-2.

37. Law SK, Huang JS, Nassiri N, Moghimi S, Nilforushan N, Parham A, Moossai J, Kim M, Caprioli J, Aldave AJ. Technique of combined glaucoma tube shunt and keratoprosthesis implantation. J Glaucoma. 2014;23(8):501-7.

38. Colby KA, Koo EB. Expanding indications for the Boston keratoprosthesis. Curr Opin Ophthalmol. 2011;22(4):267-73.

39. Lee WB, Shtein RM, Kaufman SC, Deng SX, Rosenblatt MI. Boston keratoprosthesis: outcomes and complications: a report by the American Academy of Ophthalmology. Ophthalmology. 2015;122(7): 1504-11.

40. Lee R, Khoueir Z, Tsikata E, Chodosh J, Dohlman CH, Chen TC. Longterm visual outcomes and complications of Boston keratoprosthesis type II implantation. Ophthalmology. 2017;124(1):27-35. 
41. Marchi V, Ricci R, Pecorella I, Ciardi A, Di Tondo U. Osteo-odontokeratoprosthesis. Description of surgical technique with results in 85 patients. Cornea. 1994;13(2):125-30.

42. Jirásková $N$, Rozsival $P$, Burova $M$, Kalfertova M. AlphaCor artificial cornea: clinical outcome. Eye (Lond). 2011;25(9):1138-46.

43. Falcinelli G, Falsini B, Taloni M, Colliardo P, Falcinelli G. Modified Osteo-odonto-keratoprosthesis for treatment of corneal blindness: long-term anatomical and functional outcomes in 181 cases. Arch Ophthalmol. 2005;123(10):1319-29.

44. Studeny P, Krizova D, Kuchynka P. Use of PocketMaker Microkeratome for creation of corneal pocket for foldable keratoprosthesis KeraKlear implantation - case series. Open Ophthalmol J. 2015;9:126-30.

45. Behlau I, Martin KV., Martin JN, Naumova EN, Cadorette JJ, Sforza JT, Pineda $\mathrm{R}$ 2nd, Dohlman $\mathrm{CH}$. Infectious endophthalmitis in Boston keratoprosthesis: incidence and prevention. Acta Ophthalmol. 2014;92(7):e546-55.

46. Kammerdiener LL, Speiser JL, Aquavella JV, Harissi-Dagher M, Dohlman $\mathrm{CH}$, Chodosh J, Ciolino JB. Protective effect of soft contact lenses after Boston keratoprosthesis. $B r \quad J$ Ophthalmol. 2016; 100(4):549-52.

47. Williamson SL, Cortina MS. Boston type 1 keratoprosthesis from patient selection through postoperative management: a review for the keratoprosthetic surgeon. Clin Ophthalmol. 2016;10:437-43. 
48. Boston KPro news. Update on antifungal prophylaxis in KPro patients. September 2015, Number 11. Available from: https://www.masseyeandear.org/ /media/testupload/files/kpronewslette r2015web.pdf?la=en . Accessed June 24, 2019.

49. Harissi-Dagher M, Beyer J, Dohlman $\mathrm{CH}$. The role of soft contact lenses as an adjunct to the Boston keratoprosthesis. Int Ophthalmol Clin. 2008;48(2):43-51.

50. Thomas M, Shorter E, Joslin CE, McMahon TJ, Cortina MS. Contact lens use in patients with Boston keratoprosthesis type 1: fitting, management, and complications. Eye Contact Lens. 2015;41(6):33440.

51. Li JY, Greiner MA, Brandt JD, Lim MC, Mannis MJ. Long-term complications associated with glaucoma drainage devices and Boston keratoprosthesis. Am J Ophthalmol. 2011;152(2):209-218.

52. Patel S, Takusagawa H, Shen L, Dohlman C, Grosskreutz C. Longterm complications associated with glaucoma drainage devices and Boston keratoprosthesis. Am J Ophthalmol. 2012;154(1):207-8.

53. Khan BF, Harissi-Dagher M, Khan DM, Dohlman CH. Advances in Boston keratoprosthesis: enhancing retention and prevention of infection and inflammation. Int Ophthalmol Clin. 2007;47(2):61-71.

54. Srikumaran D, Munoz B, Aldave AJ, Aquavella JV, Hannush SB, Schultze R, Belin M, Akpek EK. Long-term outcomes of Boston type 1 keratoprosthesis implantation: a retrospective multicenter cohort. Ophthalmology. 2014;121(11):2159-64. 
55. Crnej A, Paschalis El, Salvador-Culla B, Tauber A, Drnovsek-Olup B, Shen LQ, Dohlman CH. Glaucoma progression and role of glaucoma surgery in patients with Boston keratoprosthesis. Cornea. 2014;33(4):349-54.

56. de Oliveira LA, Pedreira Magalhães F, Hirai FE, de Sousa LB. Experience with Boston keratoprosthesis type 1 in the developing world. Can J Ophthalmol. 2014;49(4):351-7.

57. Panarelli JF, Ko A, Sidoti PA, Garcia JP, Banitt MR. Angle closure after boston keratoprosthesis. J Glaucoma. 2013;22(9):725-9.

58. Kang JJ, Allemann N, Cruz J De, Cortina MS. Serial analysis of anterior chamber depth and angle status using anterior segment optical coherence tomography after Boston keratoprosthesis. Cornea. 2013;32(10):1369-74.

59. Brandt JD, Casuso LA, Budenz DL. Markedly increased central corneal thickness: an unrecognized finding in congenital aniridia. $A m \mathrm{~J}$ Ophthalmol. 2004;137(2):348-50.

60. Wallace DK, Plager DA, Snyder SK, Raiesdana A, Helveston EM, Ellis FD. Surgical results of secondary glaucomas in childhood. Ophthalmology. 1998;105(1):101-11.

61. Cunliffe IA, Molteno AC. Long-term follow-up of Molteno drains used in the treatment of glaucoma presenting in childhood. Eye (Lond). 1998;12(3):379-85.

62. Arroyave CP, Scott IU, Gedde SJ, Parrish RK 2nd, Feuer WJ. Use of glaucoma drainage devices in the management of glaucoma associated with aniridia. Am J Ophthalmol. 2003;135(2):155-9. 
63. López-García JS, García-Lozano I, Rivas L, Martínez-Garchitorena J. Congenital aniridia keratopathy treatment. Arch Soc Esp Oftalmol. 2006;81:435-44.

64. Mayer KL, Nordlund ML, Schwartz GS, Holland EJ. Keratopathy in congenital aniridia. Ocul Surf. 2003;1(2):74-9.

65. Dua HS, Azuara-Blanco A. Limbal stem cells of the corneal epithelium. Surv Ophthalmol. 2000;44(5):415-25.

66. Ramaesh K, Ramaesh T, Dutton GN, Dhillon B. Evolving concepts on the pathogenic mechanisms of aniridia related keratopathy. Int $J$ Biochem Cell Biol. 2005;37(3):547-57.

67. Tseng SC, Li DQ. Comparison of protein kinase C subtype expression between normal and aniridic human ocular surfaces: implications for limbal stem cell dysfunction in aniridia. Cornea. 1996;15(2):168-78.

68. Moyer PD, Kaufman AH, Zhang Z, Kao CW, Spaulding AG, Kao WW. Conjunctival epithelial cells can resurface denuded cornea, but do not transdifferentiate to express cornea-specific keratin 12 following removal of limbal epithelium in mouse. Differentiation. 1996;60(1):31-8.

69. Sivak JM, Mohan R, Rinehart WB, Xu PX, Maas RL, Fini ME. Pax-6 expression and activity are induced in the reepithelializing cornea and control activity of the transcriptional promoter for matrix metalloproteinase gelatinase B. Dev Biol. 2000;222(1):41-54.

70. Lagali N, Edén U, Utheim TP, Chen X, Riise R, Dellby A, Fagerholm P. In vivo morphology of the limbal palisades of vogt correlates with progressive stem cell deficiency in aniridia-related keratopathy. Investig Ophthalmol Vis Sci. 2013;54(8):5333-42. 
71. Holland EJ, Djalilian AR, Schwartz GS. Management of aniridic keratopathy with keratolimbal allograft: a limbal stem cell transplantation technique. Ophthalmology. 2003;110(1):125-30.

72. Lange C, Feltgen N, Junker B, Schulze-Bonsel K, Bach M. Resolving the clinical acuity categories "hand motion" and "counting fingers" using the Freiburg Visual Acuity Test (FrACT). Graefe's Arch Clin Exp Ophthalmol. 2009;247(1):137-42.

73. Sevgi DD, Davoudi S, Talcott KE, Cho H, Guo R, Lobo AM, Papaliodis GN, Turalba A, Sobrin L, Shen LQ. A retrospective study on the outcomes of Ahmed valve versus Ahmed valve combined with fluocinolone implant in uveitic glaucoma. Digit $J$ Ophthalmol. 2017;23(3):63-70.

74. Grover S, Fishman GA, Anderson RJ, Tozatti MS, Heckenlively JR, Weleber RG, Edwards AO, Brown J Jr. Visual acuity impairment in patients with retinitis pigmentosa at age 45 years or older. Ophthalmology. 1999;106(9):1780-5.

75. Lenis TL, Chiu SY, Law SK, Yu F, Aldave AJ. Safety of concurrent Boston type I keratoprosthesis and glaucoma drainage device implantation. Ophthalmology. 2017;124(1):12-19.

76. Chew HF, Ayres BD, Hammersmith KM, Rapuano CJ, Laibson PR, Myers JS, Jin YP, Cohen EJ. Boston keratoprosthesis outcomes and complications. Cornea. 2009;28(9):989-96.

77. Belin MW, Güell JL, Grabner G. Suggested guidelines for reporting keratoprosthesis results: consensus opinion of the Cornea Society, Asia Cornea Society, EuCornea, PanCornea, and the KPRO Study Group. Cornea. 2016;35(2):143-4. 
78. Paschalis El, Taniguchi EV., Chodosh J, Pasquale LR, Colby K, Dohlman $\mathrm{CH}$, Shen LQ. Blood levels of tumor necrosis factor alpha and its type 2 receptor are elevated in patients with Boston type I keratoprosthesis. Curr Eye Res. 2019;44(6):599-606.

79. França ET, Arcieri ES, Arcieri RS, Rocha FJ. A study of glaucoma after penetrating keratoplasty. Cornea. 2002;21(3):284-8.

80. Quigley $\mathrm{H}$, Broman AT. The number of people with glaucoma worldwide in 2010 and 2020. Br J Ophthalmol. 2006;90(3):262-7.

81. Homayounfar G, Grassi CM, Al-Moujahed A, Colby KA, Dohlman $\mathrm{CH}$, Chodosh J. Boston keratoprosthesis type I in the elderly. $\mathrm{Br} J$ Ophthalmol. 2017;101(4):514-8.

82. Yaghouti F, Nouri M, Abad JC, Power WJ, Doane MG, Dohlman CH. Keratoprosthesis: Preoperative prognostic categories. Cornea. $2001 ; 20(1): 19-23$.

83. Tezel G, Li LY, Patil RV, Wax MB. TNF-alpha and TNF-alpha receptor1 in the retina of normal and glaucomatous eyes. Invest Ophthalmol Vis Sci. 2001;42(8):1787-94.

84. Črnej A, Omoto M, Dohlman TH, Gonzalez-Andrades M, Paschalis EI, Cruzat A, Vu TH, Doorenbos M, Chen DF, Dohlman CH, Dana R. Effect of penetrating keratoplasty and keratoprosthesis implantation on the posterior segment of the eye. Investig Ophthalmol Vis Sci. 2016;57(4):1643-8.

85. Sivaraman KR, Hou JH, Allemann N, de la Cruz J, Cortina MS. Retroprosthetic membrane and risk of sterile keratolysis in patients with type I Boston keratoprosthesis. Am J Ophthalmol. 2013;155(5):814-22. 
86. Rudnisky CJ, Belin MW, Todani A, Al-Arfaj K, Ament JD, Zerbe BJ, Ciolino JB; Boston Type 1 Keratoprosthesis Study Group. Risk factors for the development of retroprosthetic membranes with Boston keratoprosthesis type 1: multicenter study results. Ophthalmology. $2012 ; 119(5): 951-5$. 
Apêndice 


\section{APÊNDICE}

Os resultados da presente tese foram publicados na revista American Journal of Ophthalmology em novembro de 2019, volume 207, páginas 258 a 267: DOI10.1016/j.ajo.2019.06.018. 